\title{
Commercially Available Order Flow Data and Exchange Rate Movements: Caveat Emptor
}

\author{
Michael Sager ${ }^{a}$ and Mark P. Taylor ${ }^{b *}$ \\ ${ }^{a}$ Putnam Investments and University of Warwick. \\ ${ }^{b}$ University of Warwick and Centre for Economic Policy Research.
}

January 2006

\begin{abstract}
Research suggests that customer order flow should help predict exchange rates. We make two contributions. First, we provide a review of the recent literature on order flow and exchange rate movements. Second, we critically evaluate the practical value of customer order flow data that is commercially available to the wider market, as well as the forecasting properties of interdealer order flow. In line with microstructure theory, we find little evidence that the latter can forecast exchange rates, but our results also cast considerable doubt on the practical value to market practitioners of commercially available customer order flow data.

Keywords: Foreign exchange market; microstructure; order flow; forecasting.

JEL Classification: F31
\end{abstract}

${ }^{*}$ We are grateful to Martin Evans, Richard Lyons, Michael Melvin, Carol Osler and Giorgio Valente for comments on an earlier draft. Any remaining errors are ours alone. Corresponding author: Professor Mark P. Taylor, Department of Economics, University of Warwick, Coventry CV4 7AL, UK. E-mail: mark.taylor@warwick.ac.uk 


\section{Introduction}

Foreign exchange market order flow may be defined as transaction volume signed according to the initiator of the trade (Lyons, 2001) - positive for a buy order, negative for a sell order. It is distinct from transaction volume, since the latter is a measure of trading activity between customers and dealers, or within the interdealer market, over a given period and in a particular exchange rate without indication of the direction of these transactions. Measured as signed transaction volume, order flow therefore provides an indication of the relative strength of buy as opposed to sell orders between, say, customers and dealers. In this way, order flow within particular investor groups will not necessarily sum to zero, but can instead exhibit persistent trends - for example, if customers build a long position in a particular currency relative to an underlying strategic benchmark position, then order flow in that currency from that customer group will be positive and rising.

A central hypothesis of the foreign exchange market microstructure literature is that order flow allows the wider market to learn about the private information and trading strategies of better informed participants, and therefore represents the conduit through which information becomes embedded within market prices (see, e.g., Lyons, 1995; Rime, 2001; Evans and Lyons, 2005a,b). This hypothesis seems an intuitive explanation of the process of price discovery in the foreign exchange market. It implies that end-user, or customer, order flow will consistently be more important in the determination of exchange rate returns than interdealer order flow. In addition, order flow generally should have greater explanatory and predictive power for exchange rate returns than fundamental variables, at least at shorter horizons.

In this paper we seek to make two contributions to the microstructure literature. First, we provide an overview of the new empirical literature on order flow and exchange rate movements. Second, and more importantly, using indices on aggregated and disaggregated customer order flow data from two major investment banks, ${ }^{1}$ as well as data on interdealer order flow employed in a seminal paper in the order flow literature, ${ }^{2}$ we critically evaluate the practical value of order flow data in terms of their relationship to exchange rate movements allowing for publication lags, the direction of Granger-causality, and the accuracy of derived out-of-sample exchange rate forecasts.

There are two separate issues that should be distinguished in this discussion. One relates to the underlying economic relationship between order flow and exchange rate movements. If order flow is the means by which information concerning the evolution of fundamentals is disseminated into the market, then a contemporaneous correlation between order flow and exchange rate movements

\footnotetext{
${ }^{1}$ We thank Jan Loeys and Mustafa Caglayan at JPMorgan Chase and Peter Eggleston at the Royal Bank of Scotland for their help in obtaining the customer order flow data analysed in this paper. These data were pre-filtered and collated into indices by JPMorgan and the Royal Bank of Scotland to ensure that individual customer trades were not indentifiable from the data, thereby maintaining customer confidentiality.

${ }^{2}$ We are grateful to Richard Lyons for supplying these data.
} 
should be observed. The second issue relates to the practical value of commercially available order flow data to foreign exchange market participants. Clearly, dealers in large banks who observe order flow on a real-time, continuous basis, will be able to use that knowledge to inform their trading decisions. Most participants in the market will, however, never be able to observe that order flow data directly because the data are propriety, and instead will only be able to observe order flow data provided by certain custodian banks on a filtered rather than raw basis to ensure client anonymity, with a minimum publication lag of one day. Thus, the practical value of commercially available order flow data to many market participants depends upon whether or not the data are able to predict exchange rate movements at least one day ahead.

The remainder of the paper is organized as follows. In the next section we present a review of the microstructure literature linking order flow with exchange rate movements. The subsequent section describes our data sets and the following section presents our empirical analysis. In a final section we draw some conclusions from our analysis and provide suggestions for future research.

\section{Order Flow and Exchange Rate Dynamics: An Overview of the Recent Literature}

Order flow is initiated for a variety of reasons that differ across the various participants in the foreign exchange market. These participants include corporations, central banks, asset management firms, commodity trading advisors (CTAs), hedge funds, private individuals and investment bank dealers. ${ }^{3}$ These market participants exhibit significant heterogeneity, in terms of opportunity sets and risk-return expectations, and display distinct informational asymmetries, with some participants better informed than others. By reputation, customer order flow is the primary source of private information in the foreign exchange market (Lyons, 1995; Ito, Lyons and Melvin, 1998; Rime, 2001; Evans and Lyons, 2004; Bjønnes and Rime, 2005). This private information is typically assumed to relate to future innovations in fundamental exchange rate determinants, including monetary policy innovations (Evans and Lyons, 2004; 2006; Jansen and de Haan, 2003). But it can also incorporate knowledge of the decision-making process that triggers strategic shifts in portfolio benchmark hedge ratios in response to changes in risk appetite or return objectives independently from innovations in published fundamentals (Lyons, 2002). Similar to innovations in fundamental variables, changes in long-term investment objectives will lead to asset allocation shifts within investment portfolios, for instance between international bonds and equities, that in turn inspire order flow.

A number of empirical studies have demonstrated a contemporaneous explanatory role for order flow in exchange rate models. Most of these studies have focused, principally for reasons of data availability, upon the role of the

\footnotetext{
${ }^{3}$ See Sager and Taylor (2006) for a comprehensive discussion of the institutional microstructure of the foreign exchange market.
} 
interbank market, implicitly or explicitly maintaining the assumption that these flows embed information into prices by reacting to customer orders (Evans and Lyons, 2006), and that customer orders are the primary source of private information in the foreign exchange market.

In their path-breaking study of foreign exchange market microstructure, Evans and Lyons (2002a) analyze the ability of interdealer order flow data collected from Reuters D2000-1 to explain the daily variation of mark-dollar and yen-dollar during a four-month period from May to August 1996. To this end, Evans and Lyons regress the daily log change in each exchange rate on the daily change in interest rate differentials - their proxy for fundamentals - and daily interdealer order flow. They find that $64 \%$ of daily mark-dollar returns and $45 \%$ of yen-dollar returns can be explained within this simple framework. Moreover, on the basis of Wald exclusion tests, they find that the explanatory power of these regressions is almost wholly due to order flow (Lyons, 2001).

In a subsequent paper, Evans and Lyons (2002b) extend this analysis to an additional seven exchange rates: the price of the US dollar expressed in terms of UK sterling, Belgian, French and Swiss francs, Swedish krona, Italian lira and Dutch guilder. ${ }^{4}$ Contemporaneous correlations are more variable over this extended group, with $\overline{R^{2}}$ statistics ranging from 0.00 for the Belgian franc and Swedish krona to 0.68 for the mark (slightly higher than in the dollar-mark regression of Evans and Lyons, 2002a). In addition, Evans and Lyons also report a substantial rise in explanatory power with the inclusion in equations of order flow into other currencies - for instance, estimated $\overline{R^{2}}$ statistics rise to 0.69 and 0.78 for the Swedish krona-dollar and mark-dollar exchange rates, respectively. Although this type of cross-pollination effect of order flow between exchange rates seems intuitive - the foreign exchange market clearly does experience general dollar buying and selling trends - the sign of estimated coefficients is unstable, switching from equation to equation. Thus, net buying by dealers of sterling enters with a positive coefficient into the equation for the Belgian, Swedish and French exchange rates against the dollar, but with a negative coefficient for the mark, yen, Swiss franc, lira and guilder.

The finding of a substantial contemporaneous correlation between interdealer order flow and exchange rate returns is confirmed by Fisher and Hillman (2003) - albeit with generally lower $\overline{R^{2}}$ statistics than Evans and Lyons (2002a,b) - and Daníelsson, Payne and Luo (DPL, 2002). DPL examine Reuters D2000-2 data over a ten-month period from 1999 to 2000 using eight sampling frequencies ranging from five minutes to one week for mark-dollar, yen-dollar, sterling-dollar and sterling-mark. $\overline{R^{2}}$ statistics for mark-dollar and yen-dollar equations typically lie in the region of $0.3-0.5$ across all sampling frequencies, except for very high frequency observations for yen-dollar, which are closer to zero. Arguably, the analysis of sterling cross rates provides the most robust results, given the relative market share of Reuters D2000-2 in order flow for these exchange rates. Although DPL do find a significant role for order flow in explaining sterling returns, $\overline{R^{2}}$ statistics are generally lower and diminish dramatically

\footnotetext{
${ }^{4}$ In this paper, Evans and Lyons exclude interest differentials.
} 
for frequencies beyond one hour, suggesting a much weaker relationship than for the other exchange rates.

DPL also consider the practical relevance of their results by assessing the out-of-sample predictive power of interdealer order flow for exchange rate returns. To this end, they provide a set of results termed "genuine forecasts", by which they mean forecasts that include no perfect foresight with respect to the future values of explanatory variables. ${ }^{5}$ Largely consistent with our findings reported below, they conclude that, without perfect foresight of future explanatory variables, order flow has little or no predictive power for exchange rate returns: $\overline{R^{2}}$ statistics fall to zero, root mean squared forecast error (RMSFE) statistics are higher for forecasts based upon order flow than a naive random walk and, indeed, order flow is Granger-caused by exchange rate returns. Payne and Vitale (2002), on the basis of an examination of central bank order flow for Swiss franc-dollar over the sample period 1986 to 1995, similarly conclude that "the leads and lags of Swiss National Bank customer order flow (in Swiss francdollar) often have the wrong sign and are, in general, not significantly different from zero" (Payne and Vitale, 2002). These findings would seem, on the surface at least, to question the validity of a central hypothesis of the microstructure literature.

Other researchers have reported the existence of a significant explanatory role for order flow in exchange rate movements. Using daily data from the Electronic Broking System (EBS) between January 1998 and December 1999, Killeen, Lyons and Moore (KLM, 2006) determine the presence of a Grangercausal relationship that runs from French franc-German mark order flow to exchange rate returns. They also test for the presence of a cointegrating relationship between the exchange rate, order flow and interest rate differentials, which, in common with Evans and Lyons (2002a), they include as a proxy for macroeconomic fundamentals. KLM find in favor of the existence of one cointegrating vector, which allows them to infer the presence of long-term co-movement between these three series. Mende and Menkhoff (2003), using customer order flow tick data for euro-dollar from a medium-sized (anonymous) German bank over eighty-seven trading days from July to November 2001, report similar findings from cointegration tests.

In contrast, Rime (2001), using weekly US Treasury data for interdealer order flow of major participants in the US sector of the foreign exchange market during the period July 1995 to September 1999, reports mixed results from cointegration tests. ${ }^{6}$ He finds in favor of a cointegrating relationship between order flow and the exchange rate for mark-dollar, sterling-dollar and Swiss francdollar, but against for yen-dollar and Canadian dollar-US dollar. It is unclear

\footnotetext{
${ }^{5}$ This differentiates their approach from the traditional Meese-Rogoff (1983a, b) methodology which assumes perfect foresight with respect to forcing variables. DPL also report Meese-Rogoff forecasts; unsurprisingly, these are more favourable to the predictive ability of order flow.

${ }^{6}$ Bjønnes and Rime define a major participant as one with more than $\$ 50$ bn equivalent in foreign exchange contracts, including spot, forward and options, on the last business day of any quarter during the previous year (Bjønnes and Rime, 2001b).
} 
why this difference exists, given that all of the exchange rates share the same numéraire, unless it is indicative of the problems implied by the use of an inherently long-term hypothesis (cointegration) with a short data span. In addition, Rime (2001) concludes that inclusion of foreign equity returns generates a marked increase in the $\overline{R^{2}}$ statistics of estimated regressions, suggesting that it is primarily this variable, and not order flow, that has explanatory power for exchange rates. This is true also when perfect foresight is removed from regressions, by including lagged order flow as an explanatory variable for exchange rate returns; in this case, the explanatory power of order flow becomes insignificant for four of five exchange rates.

Overall, therefore, the various analyses of the relationship between aggregate interdealer order flow and exchange rate returns provide a number of conflicting results. In particular, none of the studies discussed above has demonstrated unequivocally that order flow has predictive power for future exchange rate returns rather than simply contemporaneous correlation. Moreover, all of the preceding studies concentrate upon an analysis of interdealer order flow. They implicitly maintain the assumption that customer orders are the main source of dispersed private information in the foreign exchange market and that the interplay between customer and interdealer orders represents the mechanism by which this information is embedded in prices.

A lack of available data has generally prevented direct analysis of customer order flow, although notable exceptions are the studies by Fan and Lyons (2003) and Evans and Lyons (2005a,b); these studies use customer order flow data from the same source, Citibank. Fan and Lyons (2003) present a qualitative event study of customer order flow disaggregated by customer type and transacted with Citibank; this institution accounts for approximately $10 \%$ of daily customer order flow (Euromoney, 2003; see Table 1). Fan and Lyons conclude that the price impact of order flow for yen-dollar and euro-dollar is differentiated by customer type, with real money flows more adept than speculative money flows at anticipating turning points in exchange rate trends. ${ }^{7}$ This finding contradicts the popular view of speculative investors as market leaders within foreign exchange (Cai, Cheung, Lee and Melvin, 2001).

In a recent paper, Evans and Lyons (2005a) examine the exchange rate forecasting power of order flow using data on customer order flow for the period January 1993 to June 1999. These raw, unfiltered data relate to three groups of customer trades with Citibank in the US dollar-euro market. ${ }^{89}$ The three customer groups correspond to non-financial corporations, real money managers

\footnotetext{
${ }^{7}$ Real money flows encompass the activities of asset management firms; speculative money flows encompass hedge funds and CTAs. The term "speculative" is used interchangeably in the literature with "leveraged".

${ }^{8}$ Before January 1999, data for the dollar-euro rate are synthesized from a weighted average of data on dollar exchange rates for what are now the Euro Area countries.

${ }^{9}$ Evans and Lyons' access to raw, unfiltered customer order flow data, in contrast to the commercially available customer order flow data examined in this paper, is very likely a crucial source of the difference between their findings and and those reported below. We return to this issue in a subsequent section.
} 
(long-term investors) and speculative traders (short-term investors). ${ }^{10}$ Evans and Lyons's forecasting results are based on regressions of the $h$-day change in the exchange rate, from day $t$ to $t+h$, onto a set of forcing variables, including order flow, at time $t$ (and employing a method-of-moments correction to the estimated covariance matrix to allow for overlapping forecast errors). ${ }^{11}$ The regressions therefore correspond to so-called 'long-horizon regressions' of the kind analyzed in the finance literature and first applied to foreign exchange rates by Mark (1995), and as reported below for some of our empirical exercises. The authors show that order flow from US corporations and US long-term investors has predictive content with respect to future exchange rate movements over horizons from one day up to one month. In Evans and Lyons (2005b), these authors also show that order flow appears to have some forecasting power for economic fundamentals such as money growth, output growth and inflation, again on a multi-month horizon. These findings - consistent with the results of Froot and Ramadorai (2005) — are particularly encouraging because they suggest that order flow does indeed provide the link between fundamentals and exchange rate movements through an information aggregation process, in line with a theoretical model that Evans and Lyons (2004) set out and develop. By contrast, Evans and Lyons (2005a) report an absence of forecasting power with respect to future exchange rate movements for both non-US order flow-from all types of investors - and order flow from short-term US investors, at any horizon. This is intriguing, because although it is reasonable to expect differences in forecasting power between the various customer types given inherent heterogeneities, it is not obvious why significant differences in forecasting power should exist between US and non-US investor flow.

Another strand of the microstructure literature considers the explanatory power of informed versus uninformed order flow for exchange rate returns. Ito, Lyons and Melvin (ILM, 1998) examine the role of informed order flow in the Tokyo sector of the foreign exchange market. They compare trading activity pre- and post-December 1994, the date of the introduction in Tokyo of previously prohibited lunchtime interdealer trading between noon and $1.30 \mathrm{pm}$. Interdealer trading should encompass relatively informed trading as it incorporates knowledge of customer activity. ILM do indeed find a significant impact on the volatility of yen-dollar returns with this change to market structure, both in terms of an increase in volatility around lunchtime as well as in the general pattern of exchange rate volatility throughout the whole Tokyo trading session. Since the flow of public information was not affected by the change in market structure, ILM (1996) conclude that volatility shifts are synonymous with the presence of private information. By implication, informed Tokyo order flow has

\footnotetext{
${ }^{10}$ We were unsuccessful in our attempts to obtain this data set from Citibank. Naturally, it was not in the power of Martin Evans or Richard Lyons to supply the data set to us, given their own confidentiality agreement with Citibank.

${ }^{11}$ In fact, Evans and Lyons report only long-horizon regressions for excess returns - that is to say with the $h$-day change in the exchange rate minus the relevant interest differential on the left-hand side. They state in the paper, however, that qualitatively identical results are obtained with respect to the significance of the order-flow terms, if the interest differential is moved the right-hand side of the regression.
} 
a predictive role for high-frequency returns to yen-dollar.

By contrast, analyzing the same data set, Anderson, Bollerslev and Das (ABD, 1998) find no evidence of a significant shift in volatility patterns caused by the change in market structure, although they do not necessarily exclude the possibility of an important role for private information in the foreign exchange market. ABD also question the efficacy of the variance ratio methodology of ILM (1998), suggesting that it will provide invalid results when applied to highfrequency data reflecting the incorrect assumption of normally distributed exchange rate returns. More supportive of the findings of ILM (1998) are the conclusions of Danílsson and Payne (2002), who examine Reuters D2000-2 order flow, bid-ask spread data and measures of order book depth for mark-dollar during one week in October 1997 and conclude that volatility shifts are associated with the presence of informed market participants in that exchange rate.

In a similar vein to ILM (1998), and using a similar data set, Covrig and Melvin (2001) establish the primacy of informed Tokyo-based Japanese traders in yen-dollar. As a result, the occurrence of a cluster of informed Tokyo-based traders generates yen-dollar quotes from Tokyo that lead quotes in this exchange rate from other trading centres, such as London or New York. Bjønnes, Rime and Solheim (2003) examine Riksbank volume trading data for the Swedish krona-euro $^{12}$ exchange rate between January 1995 and December 2001 and also conclude that the relationship between order flow and exchange rates depends upon the instigating institution. In particular, order flow instigated by large brokers that have maintained a local presence in the Swedish krona-euro market for an extended period has more price impact than the equivalent flow from relatively smaller banks that are less well established in the domestic market. Again, therefore, informed order flow appears to have a significant explanatory role for exchange rate returns. Andersen, Bollerslev, Diebold and Vega (2003) reach a similar conclusion using high-frequency returns data for a range of exchange rates over a six-year sample period. And Payne (2003), analyzing Reuters D2000-2 data for mark-dollar, concludes that $60 \%$ of variation in bid-ask spreads can be explained by asymmetric, or private, information. The magnitude and direction of the impact on spreads from private information documented by Payne is consistent with evidence from Lyons (1995). Payne thus concludes that bid-ask spreads contain a significant adverse selection component, with dealers adjusting quoted spreads to reflect the probability that they are trading with an informed market participant.

In contrast to theoretical prediction, a number of studies also conclude in favor of a significant explanatory role for uninformed, or expected, order flow. For instance, while Bjønnes, Rime and Solheim (2003) conclude that approximately one third of the volatility of daily Swedish krona-euro returns can be explained by informed order flow, they also find that uninformed flow can explain an additional one fifth of daily returns. These findings are consistent with the conclusions of Osler $(2002,2003)$, who analyses price quotation data from Reuters over the period January 1996 to April 1998 with a bootstrap methodol-

${ }^{12}$ Mark prior to January 1999. 
ogy to assess the significance of price cascades triggered by limit orders. ${ }^{13}$ She finds in favor of a significant price impact from limit orders, and therefore concludes that uninformed order flow does exert a significant impact upon exchange rates. Bates, Dempster and Romahi (2003) reach a similar conclusion examining the daily order book of another major investment bank-HSBC-over the period March to August 2002 using pattern recognition techniques derived from computational learning.

Another strand of the market microstructure literature addresses the issue of whether the strength of the relationship between order flow and exchange rates is dependent upon prevailing market conditions (Lyons, 1996; Payne, 2000; Luo, 2001; Osler, 2002). On the basis of Reuters D2000-2 data over a maximum sample of September 1999 to July 2000, and for a variety of modelling techniques and exchange rates, Luo (2001) finds in favor of a non-linear relationship between order flow and exchange rates, with the relationship stronger during periods of high bid-ask spreads and volatility, and low traded volumes. However, there is some variation in the significance of results across exchange rates, and for different measures of market conditions, suggesting that Luo's results may be overly sensitive to the sample period under study.

Osler (2002) finds statistically significant evidence in favor of the hypothesis that limit orders have a larger price impact during afternoon trading in New York, when market liquidity is traditionally relatively low, than during the New York morning trading session that overlaps the afternoon London trading session. In a similar vein, Froot and Ramadorai (2005) conclude that the relationship between exchange rate returns and order flow depends upon whether returns are permanent or temporary. In particular, order flow exhibits some explanatory power for temporary shifts in exchange rates around "fair value" levels but has no explanatory power for innovations in fair value levels. This evidence is consistent with a central hypothesis of market microstructure theory that suggests order flow should have more explanatory power for high-frequency exchange rate returns, with macroeconomic fundamentals more relevant over longer-term horizons (Lyons, 2001; Sarno and Taylor, 2002; Taylor and Taylor, 2004).

In conclusion, the preceding discussion has highlighted the variety of methodologies that researchers have adopted in an effort to assess the validity of a core hypothesis of the market microstructure literature: that order flow is the crucial link in the mechanism by which dispersed private information in the foreign exchange market becomes embedded into prices. This mechanism incorporates two stages, with customers first revealing private information to dealers, who, second, impart this information into the market in the process of spreading credit and market risk assumed from customers across the interdealer market.

\footnotetext{
${ }^{13}$ Limit orders provide the instigating party with a guaranteed price at which the associated order will be filled by the dealer, are either stop-loss or take-profit, and will be buy or sell orders depending upon the type of underlying trade (buy versus sell). Anecdotal evidence suggests that the typical size of a customer limit order is $\$ 10 \mathrm{mn}$, and has an average duration of 2 days. Dealer limit orders have an average value of $\$ 2 \mathrm{mn}$ and typically exist for just 2-3 minutes (Melvin and Wen, 2003).
} 
The results of this research have been largely inconclusive, sometimes implying a significant contemporaneous correlation between order flow and high-frequency exchange rate returns but generally - with the striking exception of Evans and Lyons (2005a) - indicating little out-of-sample predictive power. We return to a discussion of the Evans and Lyons (2005a) results in our concluding section.

An issue that has received scant attention in the literature to date, however, is whether or not customer order flow data is important to the wider market, over and above a few, privileged traders in large banks that observe actual customer orders coming through on a real-time basis, as in the confidential, proprietary data base used by Evans and Lyons (2005a). Such an analysis is important for at least three reasons. First, it is important as an additonal test of a central hypothesis of the market microstructure literature concerning the information content of order flow with respect to exchange rate movements. Second, it is important because, if the commercially available data has predictive or explanatory power for exchange rate movements, this would suggest that the use of the commercially available data by the wider market is one way in which the information in order flows becomes impounded in exchange rates. Third, at a practical level, the results are of interest to market pariticipants: is it worth buying this data as an aid to exchange rate trading decisions?

We now turn to such an analysis of commercially available customer order flow data. At the same time, we shall also examine the predictive information content of the interdealer order flow data used in the seminal paper by Evans and Lyons (2002a).

\section{Data}

We examine the relationship between order flow and exchange rate returns using three databases, one of interdealer order flow and the others of customer order flow from two major investment banks. Our first data set was kindly provided by Richard Lyons and is identical to the data set used in Evans and Lyons (2002a). It contains eighty daily observations on interdealer order flow for mark-dollar and yen-dollar during the period May 1st to August 29th, 1996. ${ }^{14}$ These data were originally collected from the Reuters D2000-1 interdealer service and are defined as the difference between the number of buyer-initiated and sellerinitiated trades. We examine these data in order critically to assess the results of Evans and Lyons (2002a), to test the validity of their stated causal relationship from order flow to exchange rates, to assess the predictive value of interdealer order flow and to test the robustness of their results to the introduction of publication lags.

Our second data set was provided by JPMorgan Chase (JPM). This institution accounts for about $7 \%$ of daily customer foreign exchange order flow, equivalent to approximately US\$4.6 billion (Euromoney, 2003); as reported in Table 1, this represents the fourth largest market share. This data set comprises

\footnotetext{
${ }^{14}$ Throughout our analysis, all exchange rates are defined as the domestic price of foreign currency.
} 
JPM's FX Flow Indicator (FXI), which incorporates raw data collated from the bank's global book of business on the aggregate daily US dollar amount of net purchases of a particular currency from all other currencies transacted with JPM through its custody business (JPMorgan, 2002). The data span the period January 1, 1999 to June 9, 2003, or 1151 daily observations, for US dollar, euro, yen, sterling and Swiss franc.

Raw JPM customer flow data are manipulated in three steps to generate the FXI. First, daily flow into currency $i$ is divided by the average absolute daily net flow into this currency over the past twelve months; this provides some indication of the strength of net daily flows into currency i. Second, this scaled daily flow is multiplied by 100 to generate an index. Third, this index is smoothed using a five-day moving average. This smoothed index is the FXI. A value of +100 for the FXI of currency $i$ indicates net inflows during the past five days equivalent to the average inflow for the last year (JPMorgan, 2002). The FXI is reported with a one day lag. ${ }^{15}$

Our third data set was provided by the Royal Bank of Scotland (RBS). This institution accounts for about $3 \%$ of daily customer foreign exchange order flow, equivalent to approximately US $\$ 2.0$ billion (Euromoney, 2003); from Table 1, this is the twelfth largest market share. Our data set comprises RBS's FX Flow Index (FFI), for euro-dollar, yen-dollar, sterling-dollar and Swiss franc-dollar, over the period October 1, 2001 to 15 May, 2003. The index is scaled to lie within the values +1 (all buys) and -1 (all sells).

\section{Empirical Results}

\subsection{The Evans-Lyons data set}

In their influential study of foreign exchange market microstructure, Evans and Lyons (2002a) analyze the ability of interdealer order flow data to explain daily variation of mark-dollar and yen-dollar during the period May through August 1996. A visual examination of the data suggests a number of interesting features. First, and consistent with the discussion above on trading strategies, cumulative interdealer order flow appears to be relatively persistent for yen-dollar, with no tendency to revert back towards zero. And although mark-dollar order flow is less persistent, the half-life of deviations from zero still appears inconsistent with the traditional academic assumption that interdealer inventory positions are reduced to zero at the end of every trading day due to the absence of overnight risk budgets. Second, there is a high contemporaneous correlation between the order flow series and the associated exchange rates, with correlation coefficients of 0.80 for mark-dollar and 0.77 for yen-dollar. At a purely subjective level,

\footnotetext{
${ }^{15}$ The raw data are manipulated in this manner primarily to ensure customer confidentiality. This applies equally to the RBS order flow data discussed below. Although this manipulation will dilute the information content of these data, this is an important characteristic: a small group of preferred customers are allowed access to these data manipulated data. Only dealers of the owning institution see the raw flow, on a real-time-albeit uncollated-basis.
} 
therefore, evidence exists to support the hypothesis that interdealer order flow has some explanatory power for the behavior of daily exchange rate returns.

To examine this relationship more rigorously, Evans and Lyons (2002a) estimate the following equation by ordinary least squares (OLS):

$$
\Delta s_{t}=\beta_{1} \Delta\left(i_{t}-i_{t}^{*}\right)+\beta_{2} X_{t}+\eta_{t},
$$

where $\Delta s_{t}$ is defined as the daily log change in the exchange rate from 4.00 p.m. GMT on day $t-1$ to the same time on day $t ; \Delta\left(i_{t}-i_{t}^{*}\right)$ is the change over the same period in the one-day domestic-foreign interest differential, which is the authors' proxy for relevant exchange rate fundamentals; $X_{t}$ is interdealer order flow between 4.00 p.m. GMT on day $t-1$ and the same time on day $t$; and $\eta_{t}$ is a white-noise error term.

On the basis of their empirical estimates of equation (1), Evans and Lyons (2002a) conclude that interdealer order flow data can explain a significant proportion of contemporaneous daily exchange rate variation. Our reworking of their analysis yields similar results (Table 2). ${ }^{16}$ The $\overline{R^{2}}$ of the estimated equation, assuming no publication lags, is 0.64 for mark-dollar and 0.44 for yendollar. This is an impressive result, particularly as it relates to daily returns which, traditionally, are assumed to be distributed as random. Furthermore, the estimated coefficients for explanatory variables in both equations are correctly signed and significant.

Omitting order flow from equation (1) and simply regressing exchange rate returns on the change in the interest differential reduces the $\overline{R^{2}}$ statistic in both cases to below 1\%, and renders estimated coefficients insignificant at the $5 \%$ level. This leads Evans and Lyons (2002a) to conclude that daily variation in both exchange rates is largely explained by interdealer order flow, with little role at this frequency for fundamental variables. To this end, we are able to confirm their finding, on the basis of a Wald test, that the change in significance in the interest differential between the two specifications is consistent with omitted variable bias in the simplified equation (Evans and Lyons, 2002a). Accordingly, on the basis of the evidence presented so far, daily interdealer order flow has significant explanatory power for daily exchange rate returns. ${ }^{17}$

As it stands, this is an extremely interesting result and is certainly worthy of further consideration, on three counts: publication lags; Granger-causality; and the accuracy of associated exchange rate forecasts.

\subsubsection{Publication lags}

As discussed above, there are two facets to the market microstructure literature: explanation and prediction. The results of Evans and Lyons (2002a)

\footnotetext{
${ }^{16}$ Our results differ only very slightly from Evans and Lyons (2002a), probably due to computer software differences.

${ }^{17}$ Unless stated to the contrary, we use a nominal test size of $5 \%$ throughout this paper and terms such as 'significant' and its derivatives should be understood as such unless directly qualified.
} 
demonstrate the important explanatory role that order flow occupies in foreign exchange price discovery. But any viable investment strategy that aims to exploit the hypothesized predictive power of order flow for exchange rates can incorporate only data publicly available in advance of the introduction of active currency hedges into portfolios. ${ }^{18}$ Evans and Lyons (2002a) explain daily exchange rate returns from period $t-1$ to $t$ using contemporaneous order flow and interest rate data. This implies full information with respect to future values of the interest rate differential and order flow. Correcting for this means introducing a one-day lag into both explanatory variables in equation (1) :

$$
\Delta s_{t}=\beta_{1} \Delta\left(i_{t-1}-i_{t-1}^{*}\right)+\beta_{2} X_{t-1}+\eta_{t}
$$

The estimation results from the revised equation (2) are presented in Table 2: with appropriate publication lags, the relationship between daily exchange rate returns and interdealer order flow becomes insignificant, and the $\overline{R^{2}}$ of equations for both yen-dollar and mark-dollar falls virtually to zero.

\subsubsection{Granger-causality}

We perform Granger-causality tests to examine whether order flow tends systematically to precede exchange rate movements or follow them. The results are given in Table 3, and show that a significant Granger-causal relationship runs from exchange rate returns to order flow for both exchange rates (albeit only at a $10 \%$ significance level for yen-dollar).

\subsubsection{Forecast Accuracy}

Although contemporaneous explanatory power is certainly interesting, it is also instructive to test the forecasting ability of order flow with respect to exchange rate movements. In a companion paper to Evans and Lyons (2002a), Evans and Lyons (2001) report RMSFEs of exchange rate forecasts for mark-dollar and yen-dollar over one-day, and one- and two-week horizons derived from a naive random walk and a recursive estimation of the Evans and Lyons (2002a) regression equation (1). These forecasts take the form:

$$
\widetilde{s}_{t+k}-s_{t}=\sum_{j=1}^{k} \widetilde{\Delta s}_{t+j}=\widehat{\beta}_{1} \sum_{j=1}^{k} \Delta\left(i_{t+j}-i_{t+j}^{*}\right)+\widehat{\beta}_{2} \sum_{j=1}^{k} X_{t+j}
$$

for $k=1,5,10$, where a circumflex denotes the fitted value of the coefficient using data up to time $t$, and a tilde denotes the forecast value of the exchange rate. The forecasts are subjected to the now-traditional Meese-Rogoff (1983a,b) evaluation criteria. These criteria involve, in this application, using data over

\footnotetext{
${ }^{18}$ For a discussion of active versus passive foreign exchange investment strategies, see Sager and Taylor (2006).
} 
the initial thirty-nine observations of the Evans and Lyons data set to generate initial coefficient estimates of the relationship between exchange rates, interdealer order flow and interest differentials. This estimated relationship is then used to forecast the change in the exchange rate at time $t+k$ based upon observed values of order flow and interest differentials also at time $t+k$. These initial coefficient estimates are then recursively updated, and the forecasting exercise repeated. Consequently, the Meese-Rogoff criteria assume full information (perfect foresight) with regard to the future values of explanatory variables. We replicate this analysis in Table 4 . Consistent with the results of Evans and Lyons (2001), we conclude that the use of interdealer order flow under the assumption of full information with respect to future interest rate differentials and order flow generates more accurate forecasts than a random walk model across all horizons and for both exchange rates.

In order to assess the statistical significance of this improvement in forecast accuracy, we calculate the Diebold-Mariano (DM; Diebold and Mariano, 1995) test statistic for equality of forecast accuracy. ${ }^{19}$

As we report in Table 4, the DM test statistic indicates that the reduction in forecast errors achieved by modelling daily exchange rate returns as a function of interdealer order flow and interest differentials within the Evans and Lyons (2002a) framework in place of a random walk model is not statistically significant at conventional nominal test sizes, at any of our forecast horizons.

The assumption of perfect foresight of future explanatory variables implicit within the Meese-Rogoff criteria is clearly not, moreover, appropriate in a realtime investment portfolio context. Accordingly, we repeat the above analysis

\footnotetext{
${ }^{19}$ The DM test statistic can accommodate a wide variety of features relating to forecast errors, including non-zero means, non-normality and contemporaneous correlation between rival prediction methods applied to the same time series. It is defined as:

$$
D M=\frac{\bar{d}}{\sqrt{\frac{2 \pi f(0)}{N}}}
$$

where $\bar{d}$ is an average over $N$ forecast periods of a general loss function $d_{x}$ such as the difference in squared forecast errors

$$
\left(d_{k}=\left[\zeta_{k}^{(1)}\right]^{2}-\left[\zeta_{k}^{(2)}\right]^{2}\right)
$$

or in absolute errors

$$
\left(d_{t}=\left|\zeta_{k}^{(1)}\right|-\left|\zeta_{k}^{(2)}\right|\right)
$$

that is, $\bar{d}=\frac{1}{N} \sum_{k=1}^{N} d_{k}$ for $N=1, . ., 42$ in our recursive application; $\widehat{f}(0)$ is a consistent estimate of the spectral density of the loss differential function at frequency zero, which we estimated using the method of Newey and West (1987). Under certain regularity conditions the DM test statistic will be distributed as standard normal under the null hypothesis of equal forecast accuracy (Diebold and Mariano, 1995). The distribution of the DM test statistic is, however, unclear in small samples. Consequently, marginal significance levels reported below should be interpreted with caution.
} 
using only data available at the date exchange rate forecasts are compiled, that is

$$
\begin{aligned}
\widetilde{s}_{t+k}-s_{t} & =\sum_{j=1}^{k} \widetilde{\Delta s_{t+j}}=\widehat{\beta}_{1} \sum_{j=1}^{k} \Delta\left(i_{t}-i_{t}^{*}\right)+\widehat{\beta}_{2} \sum_{j=1}^{k} X_{t} \\
& =\widehat{\beta}_{1} k \Delta\left(i_{t}-i_{t}^{*}\right)+\widehat{\beta}_{2} k X_{t}
\end{aligned}
$$

for $k=1,5,10$. This differs from equation (3) in that we have used only the current value of the interest differential and the order flow term, rather than assuming perfect foresight of values of them at times $t+j$ for $j>0$. We term these limited information forecasts, and report the results in Table 5. In this case, and at all horizons, RMSFE statistics associated with the random walk forecasts are lower for both exchange rates than those generated by the Evans and Lyons model. Furthermore, DM test statistics indicate that this reduction in RMSFEs in favor of the random walk model is significant, other than at a one-day horizon for yen-dollar. Under realistic trading conditions, therefore, the Evans-Lyons model generates exchange rate forecasts that are significantly inferior to a naive random walk.

\subsubsection{Long-horizon regressions}

We also compute a series of long-horizon forecasts on the basis of Evans and Lyons (2002a). Long-horizon forecasts are a standard means of assessing whether a variable has predictive content (see e.g. Mark, 1995; Kilian and Taylor, 2003), and in the present context take the form,

$$
s_{t+k}-s_{t}=\beta_{1 k} \Delta\left(i_{t}-i_{t}^{*}\right)+\beta_{2 k} X_{t}+\varepsilon_{t+k}
$$

for $k=1,2, \ldots, 10$. Table 6 reports the p-values (marginal significance levels) associated with estimated coefficients at forecast horizons from one to ten days. These p-values are calculated using a non-parametric bootstrap that involves 5000 simulations where the data have been generated from a naive random walk model for both exchange rates over every forecast horizon (see Kilian and Taylor (2003) for further details of the bootstrap procedure). The significance of the estimated coefficients gives an indication of the importance of the interest differential and of order flow in predicting exchange rate movements at various horizons.

Consistent with the limited information forecasts above, the results of longhorizon forecasts indicate that interdealer order flow has no significant predictive power for daily exchange rates returns at any horizon. Interest differentials are also generally insignificant, although at intermediate horizons for mark-dollar some evidence of weak significance for this variable is apparent. 


\subsubsection{The Evans-Lyons Customer Order-Flow Data: Summing Up}

We can conclude this examination of the Evans-Lyons data set as follows. Evans and Lyons (2002a) present an excellent in-sample explanation of daily exchange rate variation that emphasizes the importance of order flow over fundamental variables for data samples that incorporate high-frequency observations. Their findings represent an important step in improving our understanding of the transmission mechanism by which dispersed private information is embedded into prices in the foreign exchange market. Disappointingly, however - and yet consistent both with the general experience of the past three decades of empirical exchange rate modelling and with microstructure theory (Evans and Lyons, 2005b) - the predictive power of interdealer order flow data, albeit on the basis of a very short time span, is poor and implies that these data, sampled on a daily frequency, cannot be used to improve the quality of exchange rate forecasting or investment portfolio decision-making.

\subsection{JP Morgan Chase (JPM) FXI Aggregate Customer Order Data}

It is an open question whether predictive performance can be improved using alternative sources of order flow, and particularly customer data. Intuitively, this approach should lead to some improvement as customer orders arguably represent the main source of private information in the foreign exchange marke. Evans and Lyons (2005a) report impressive forecasting results using disaggregated customer order flow from Citibank. But these data are available only to Citibank traders to exploit and not the wider market. Consequently, these results have limited applicability. To understand the ability of customer order flow data available to the wider market to forecast exchange rate returns we examine customer order flow from JP Morgan Chase (JPM), and, below, from the Royal Bank of Scotland (RBS). Both data series are made available to real money and speculative money clients of these institutions, are representative of similar data made available to clients by other institutions - including HSBC and State Street - and so are more representative than the Citibank order flow examined by Evans and Lyons (2005a).

Our next step is to re-estimate the Evans and Lyons (2002a) model using the JPM FXI database for each of the four exchange rates. The results of this exercise, with and without appropriate publication lags, ${ }^{20}$ are reported in Table 7. As the FXI is defined as net inflows into a particular currency from all other currencies, we have included separately in the regression equation both net inflows into the currency and into the dollar; as the predominant currency within bond and equity indices, the dollar order flow is included as a proxy for flows into all other currencies. ${ }^{21}$ Thus, the regression equation becomes:

\footnotetext{
${ }^{20}$ These data are published with a one day lag (i.e. $\mathrm{t}+1$ ).

${ }^{21}$ Although these order flow data are expressed as net purchases of currency $i$ from all other currencies we replicate the bilateral exchange rate analysis of Evans and Lyons (2002a). As the US dollar is on one side of $89 \%$ of all foreign exchange transactions (BIS, 2005), our approach
} 


$$
\Delta s_{t}=\beta_{1} \Delta\left(i_{t}-i_{t}^{*}\right)+\beta_{2} X_{t}^{D O M}+\beta_{3} X_{t}^{U S}+\eta_{t},
$$

where $X_{t}^{D O M}$ denotes the net order flow into the currency concerned (the "domestic" currency) and $X_{t}^{U S}$ denotes the net order flow into the US dollar.

The most striking contrast between the results reported in Tables 7 and 3 is the magnitude of estimated $\overline{R^{2}}$ statistics. Using JPM data, and assuming no publication lags, a maximum of just $2 \%$ of daily exchange rate variation is explained by the Evans and Lyons model. This is far worse than the results of estimated equations that use interdealer order flow, and can at least partly be explained by the extent that the raw order flow data have been manipulated to ensure customer anonymity.

The magnitude of absolute coefficient estimates for order flow reported in Table 7 do not lend themselves to economic interpretation given the extent of data manipulation. But the sign and relative magnitude of estimated coefficients are instructive: coefficient signs on both order flow terms are consistent with a priori expectations for all four exchange rates, with net purchases of domestic currency (dollars) consistent with an appreciation (depreciation) of the exchange rate. $^{22}$ Coefficients are statistically significant for net purchases of euros and Swiss francs, and for US dollar purchases for yen-dollar, sterling-dollar and Swiss franc-dollar. In addition, the magnitude of estimated coefficients indicates that the strongest contemporaneous relationship between net purchases of domestic currency and exchange rate returns exists for Swiss franc-dollar.

Estimated coefficients for the interest differential term are also consistent with a priori expectations, except for sterling, where an increase in domestic interest rates relative to US rates is found to be consistent with an appreciation of the domestic currency.

\subsubsection{Publication Lags}

Consistent with our re-examination of the Evans and Lyons (2002a) data, explanatory power falls to zero for all exchange rates once appropriate publication lags have been incorporated (equation (2)). Furthermore, coefficient estimates in Table 7 are now insignificantly different from zero, except for interest differentials which are weakly significant for sterling-dollar (but still incorrectly signed). In addition, inclusion of a one-day publication lag causes the sign of many coefficients to switch.

approximates reality. In addition, market participants typically focus active currency decisions upon bilateral, rather than trade-weighted, exchange rates.

${ }^{22}$ Coefficient signs on the order flow variable in the no-lag variant are reversed compared with the Evans and Lyons results in Table 3. This reflects a difference in the construction of these data between the different sources: in the Evans and Lyons data a positive order represents a purchase of dollars; in this case it represents a sale. 


\subsubsection{Granger-causality}

Granger-causality tests between JPM FXI customer order flow data and exchange rate returns also offer little reason for optimism (Table 8). Contrary to theoretical prediction, causality runs strictly from exchange rate returns to customer order flow for euro-dollar, sterling-dollar and Swiss franc-dollar. For yen-dollar, there is evidence of two-way causality between returns and net purchases of the domestic currency; for net dollar purchases, the strict, perverse causal relationship observed for other exchange rates is evident also for this exchange rate.

The general presence of a perverse causal relationship between order flow and exchange rate returns could reflect a number of factors. First, it may simply be that aggregate customer order flow available to the wider market has no predictive value for exchange rate returns. This conclusion, which we examine in more detail below, is consistent with the view of Andersen, Bollerslev and Das (1998), who suggest that market microstructure theories are typically not designed to provide quantitative predictions, but merely a qualitative characterization of the pattern that is likely to arise in some market variables, including exchange rate returns.

Second, JPM FXI order flow data may simply be unrepresentative of market trends, regardless of publication lags. This may in turn be due either to a relatively small absolute market share for JPM within total customer order flows, or to pre-filtering of the raw order flow data that greatly diminishes their information content. Both explanations are certainly possible. Although JPM boasts the fourth largest market share in the customer order space of the foreign exchange market, it transacts only $7 \%$ of total daily turnover (Euromoney, 2003). It is an impossible task, however, to aggregate customer order flow data across transacting banks to achieve a database that unequivocally covers a critical mass of market share, for a number of reasons. Crucially, most investors do not have access to two or more order flow data sets, and many do not enjoy access even to one. For those that do have access to two or more, differences in data measurement and aggregation make the task of compiling a composite database impractical. Similarly, it is an unavoidable fact that practitioners outside of the owning institution gain access - at best - only to pre-filtered, indexed order flow data. This filtering, necessary to ensure customer anonymity, must dilute the information content of the data, potentially to the point of rendering them practically useless as inputs into exchange rate forecasting models.

\subsubsection{Forecast Accuracy}

Table 9 reports the RMSFEs of forecasts prepared under the Meese-Rogoff (1983a, b) perfect foresight assumption concerning future explanatory variables, and using JPM customer order flow data within both the Evans and Lyons and random walk models. As above, forecasts are calibrated over one-day, and one and two-week horizons. The final column in Table 9 reports the associated DM test statistic, with a negative value indicative of an improvement in forecast 
accuracy moving from the random walk to the Evans and Lyons model.

The results of this exercise indicate that forecast errors generated by the Evans and Lyons model incorporating JPM FXI customer order flow data are generally smaller than those generated by the random walk model. In addition, DM test statistics indicate that this improvement is statistically significant in many cases. This is a marked improvement on the results derived from interdealer order flow.

This improvement in forecast accuracy does not transfer to limited information forecasts, however. As Table 10 indicates, for euro-dollar, yen-dollar and Swiss franc-dollar, the random walk model now generates a statistically significant reduction in forecast errors compared with the Evans and Lyons model. For sterling-dollar, forecast errors generated by the random walk model are consistently smaller than the Evans and Lyons model, but this improvement is only significant at a two-week horizon.

\subsubsection{Long-horizon regressions}

In Table 11 we report p-values for long-horizon forecasts from one to ten days ahead. For euro-dollar and Swiss franc-dollar, these forecasts fully confirm the results of the preceding analysis: customer order flow provides no improvement in forecast accuracy relative to a naive random walk. Indeed, the only significant coefficient at the $5 \%$ level for either of these exchange rates is for euro-dollar interest differentials for a four-day-ahead horizon; we are inclined not to put too much emphasis upon this result, given its relative isolation. In addition, for both exchange rates tests indicate that estimated coefficients are jointly insignificantly different from zero at each forecast horizon.

For yen-dollar and sterling-dollar, the results are a little more favorable to a link from order flow to exchange rate dynamics. For yen-dollar, net purchases of domestic currency have a significant explanatory role for exchange rate returns from six to ten days ahead. This result may be consistent with the finding above of two-way causality between exchange rate returns and net purchases of yen, with particular customer groups reacting to an earlier move in yen-dollar by subsequently adjusting their positions in this exchange rate. Most logically, this argument should apply to corporations who adjust their hedging behavior depending upon the level of the exchange rate, and technical and model-based investors who invest on the basis of directional trend analysis. Taken together, all three coefficients for yen-dollar are jointly insignificant at every horizon.

For sterling-dollar, the results are somewhat perplexing. Net purchases of sterling exhibit no significant explanatory power for exchange rate returns at a $5 \%$ level, although for horizons beyond six days there is some evidence of weak significance. By contrast, net purchases of US dollars, our proxy for order flow into all other currencies, is significant at all forecast horizons except ten days ahead. The interest rate term is also significant at a few horizons. In addition, at intermediate horizons estimated coefficients are jointly significant. It is not clear why net customer order flow into other currencies would be significant for the behavior of future sterling-dollar exchange rate returns when net purchases 
of sterling are not. Given all of the accumulated evidence above that aggregate JPM customer order flow generally is not a significant explanatory variable of sterling-dollar returns, we are inclined to caution against attaching too much significance to this result. Analysis of additional customer order flow data will allow us to consider the validity of this result further, and it is to this analysis that we now turn.

\subsection{Royal Bank of Scotland FFI Aggregate Customer Or- der Data}

We repeat the analysis of customer order flow, for the same four exchange rates, using aggregate customer data from RBS. This data set comprises daily observations from October 1, 2001 to 15 May, 2003. The results of the reworking of the Evans and Lyons model (equation (1)) with these data are patchy (Table 12). Estimated order flow coefficients are correctly signed but not significant at a $5 \%$ level for euro-dollar and sterling-dollar. For yen-dollar and Swiss francdollar, the converse is true: coefficients are significant, but wrongly signed. $\overline{R^{2}}$ statistics are generally close to zero; the sterling-dollar equation achieving the highest explanatory power, at $6 \%$. Estimated coefficients for the interest rate term are generally consistent with previous academic findings that contradict uncovered interest parity. These results are much worse than the results of Evans and Lyons (2002a).

\subsubsection{Publication Lags}

Once we remove perfect foresight or full information with respect to future explanatory variables (i.e. interest rates and order flow), order flow coefficients become insignificant for all exchange rates, and explanatory power remains poor (Table 12). Evidence of coefficient sign switching between exchange rate equations is consistent with the findings of Evans and Lyons (2002b) and Lyons (2003) and suggests that the underlying relationship exploited by the Evans and Lyons (2002a) model is unstable.

\subsubsection{Granger-causality}

Granger-causality tests on aggregate FFI data are reported in Table 13. They indicate a significant causal relationship for yen-dollar that runs from exchange rate movements to customer order flow. A similar, albeit weakly significant, result is evident for Swiss franc-dollar. For none of our four exchange rates does FFI customer order flow Granger-cause exchange rate returns. These findings are largely consistent with the results from interdealer and JPM aggregate customer order flow data.

\subsubsection{Forecast Accuracy}

Table 14 reports the results of one-day, and one and two-week forecasts evaluated under Meese-Rogoff (1983a,b) criteria. For yen-dollar, DM test statistics 
indicate a significant improvement in forecast accuracy moving from the naive random walk to the Evans and Lyons (2002a) model incorporating aggregate customer order flow at both one and two week horizons, and an insignificant improvement at a one-day horizon. For euro-dollar and Swiss franc-dollar thisinsignificant-improvement is also evident for one- and two-week horizons. By contrast, for sterling-dollar the random walk model generates smaller forecast errors than the Evans and Lyons model.

When we relax the assumption of perfect foresight of future explanatory variables (Table 15), results generally look very different. For euro-dollar, the Evans and Lyons models now achieve an insignificant improvement in forecast accuracy relative to the random walk model at a one day horizon. For all other horizons and for all exchange rates, the random walk model generates smaller forecast errors than the Evans and Lyons model. In the case of yen-dollar and sterling-dollar, this improvement in favor of the random walk model is significant for one and two week ahead forecasts.

\subsubsection{Long-horizon regressions}

Moving to the long horizon forecasts (Table 16), reported p-values provide scant evidence in favor of order flow as a predictor of exchange rate returns. Excluding isolated evidence of a - weakly - significant relationship at a two-day horizon for euro-dollar, and four and ten days for yen-dollar, these results are generally consistent with the preceding findings from interdealer and JPM customer order flow. Although order flow intuitively represents the mechanism by which dispersed private information becomes embedded within exchange rates, knowledge of this mechanism and real-time access to available sources of interdealer or customer order flow data - filtered and indexed to maintain customer confidentiality - appears to be of no practical value to either forecasters or investment portfolio managers.

\subsection{Royal Bank of Scotland FFI Disaggregated Customer Order Data}

Beyond the issues of data manipulation and market share that we have already discussed, our lack of success in generating results generally supportive of the core hypotheses of the market microstructure literature may reflect our concentration so far upon aggregate customer order flow. Marked heterogeneities exist within the customer segment of the foreign exchange market that imply differences in the way various customers react to news (Lyons, 2003). Intuitively, a currency overlay manager should exhibit a different trading pattern to a CTA, and a corporation's hedging activity will be different to the foreign exchange activity of a central bank. Knowledge of the types of customers prevalent in the market at any given time and of the ways in which they trade and interact with the wider market should help foster a broad understanding of the behavior of an exchange rate at that time. Consequently, an examination of customer order flow disaggregated by customer type may uncover more supportive evidence 
for the role of market microstructure in price determination (Evans and Lyons, 2005b, 2006).

Accordingly, our final data set, also provided by RBS, separates customer order flow into four distinct customer groupings: corporations, real money managers, leveraged money managers and other customers. This final category includes central banks, non-leveraged system accounts and non-reciprocal banks. ${ }^{23}$ Clearly, even our disaggregated data are, for reasons of client confidentiality, pre-filtered and manipulated into individual indices for each of the four subgroups. Furthermore, the allocation of RBS clients into these categories will be arbitrary to a degree, with some participants spanning more than one bucket, for instance a number of currency overlay managers also offer clients leveraged currency products. Nonetheless, these data represent a unique opportunity to quantitatively test the core hypotheses of the market microstructure literature based on order flow data from a major investment bank. Although other studies have examined disaggregated customer order flow, this analysis has either been qualitative (Fan and Lyons, 2003), based upon order flow data unavailable to the wider market (Evans and Lyons, 2005b, 2006) or upon order flow data provided by a non-reciprocal bank in a minor exchange rate (Bjønnes, Rime and Solheim, 2003). To the best of our knowledge, this is the first study that has quantitatively assessed the value of disaggregated customer order flow available to the wider market from a major investment bank on a real-time basis across a number of the most liquid exchange rates.

\subsubsection{Publication Lags}

As in previous sections, we re-estimate the Evans and Lyons (2002a) model both with and without allowance for publication lags, this time replacing interdealer order flow in the original specification with our four disaggregated customer order flow series. Thus, the modified Evans-Lyons regression equation is of the form:

$$
\Delta s_{t}=\beta_{1} \Delta\left(i_{t}-i_{t}^{*}\right)+\beta_{2} X_{t}^{C}+\beta_{3} X_{t}^{R}+\beta_{4} X_{t}^{L}+\beta_{5} X_{t}^{O}+\eta_{t},
$$

where $X_{t}^{I}$ denotes customer order flow for the four groups, $I=C$ for corporate customers, $I=R$ for real money managers, $I=L$ for leveraged money managers, and $I=O$ for other customers.

This exercise provides a number of interesting results (Table 17). The $\overline{R^{2}}$ statistics remain generally close to zero, except for sterling-dollar, where $10 \%$ of daily variation is explained by this variant of the Evans and Lyons model. Again, this is much lower than the results of Evans and Lyons (2002a) using interdealer order flow.

Introducing publication lags, the regression equation becomes:

\footnotetext{
${ }^{23}$ Non-reciprocal banks are defined as smaller banks that make prices in their local markets but that are price-takers in the wider foreign exchange market, outsourcing their liquidity requirements in major exchange rates to larger investment banks, such as JPM or RBS.
} 


$$
\Delta s_{t}=\beta_{1} \Delta\left(i_{t-1}-i_{t-1}^{*}\right)+\beta_{2} X_{t-1}^{C}+\beta_{3} X_{t-1}^{R}+\beta_{4} X_{t-1}^{L}+\beta_{5} X_{t-1}^{O}+\eta_{t} .
$$

Allowing these lags into the estimation (Table 17) causes the explanatory power of the sterling-dollar equation to fall back to $5 \% .^{24}$

Although the magnitude of estimated coefficients again cannot readily be interpreted, their sign and significance are instructive. A number of the coefficients are significant, bearing out the predictions of the microstructure literature. But this result is greatly impacted by the inclusion of publication lags, and there is also evidence of parameter instability and sign switching between the perfect foresight and lagged versions of the model that cautions against placing too much emphasis on the significance of these results. Interestingly, there are no significant coefficients for euro-dollar regardless of whether or not allowance is made for publication lags.

\subsubsection{Granger-causality}

For all exchange rates Granger-causality tests reveal no significant causal relationships running from disaggregated order flow to exchange rate returns. By contrast, net yen purchases by corporations and leveraged money managers (that is, hedge funds and CTAs) are Granger-caused by exchange rate returns; this last result is consistent with the findings of Fan and Lyons (2003) who conclude that leveraged money managers provided liquidity to the market at the time of the substantial appreciation of yen-dollar during October 1998. Grangercausality running from exchange rate returns to leveraged money manager order flow is also apparent for Swiss franc-dollar, and the same result is evident for sterling-dollar corporate order flow. This perverse causal relationship for leveraged money manager order flow may reflect the predominance at short horizons of technical, trend-following investors whose investment style by design is reactive to price innovations. A similar argument applies to the hedging activity of corporations, as suggested also by the correlation analysis above.

\subsubsection{Forecast Accuracy}

The results of Meese-Rogoff forecasts using disaggregated customer order flow are generally consistent with the findings from JPM and RBS aggregate customer order flow data (Table 19). For every forecast horizon and exchange rate, except euro-dollar at one day, the Evans and Lyons model achieves an improvement in forecasting accuracy relative to a naive random walk. DM test statistics indicate that these improvements are more widely significant than is the case for either of the aggregate databases discussed above. Leaving to one side issues of perfect foresight of future explanatory variables, these results would suggest that disaggregated customer order flow data do indeed have a greater in-sample ability to predict exchange rate returns than either daily interdealer or aggregate customer order flow.

\footnotetext{
${ }^{24}$ These data are published with a one day lag.
} 
This inference, however, depends critically upon the assumption of perfect foresight with respect to future order flow and interest rate differentials (the explanatory variables). In Table 20, we relax this assumption. As indicated by the DM test statistic, the random walk model now generates more accurate forecasts than the Evans and Lyons (2002a) model, except for Swiss franc-dollar at a one-day horizon. In addition, this improvement is statistically significant in many cases.

\subsubsection{Long-horizon regressions}

From Table 21 the results of long horizon forecasts provide scant evidence of significant forecasting power. Indeed, the only real pocket of information exists for net yen purchases by real money managers on a three to five-day horizon; and Wald tests indicate joint insignificance of coefficients for all exchange rates at every forecast horizon.

In the light of these forecasting results, as well as persistent evidence of the low explanatory power and perverse Granger-causality throughout much of our analysis of both aggregate and disaggregated customer order flow data, it is difficult to avoid the conclusion that order flow, in the form available to the majority of practitioners, has little or no ability to predict exchange rate movements.

\section{Conclusion}

Traditional models of exchange rate determination concentrate upon the relationship between exchange rate movements and innovations in economic fundamentals. Their ability to explain in-sample exchange rate returns has been persistently low (Frankel and Rose, 1996; Taylor, 1995), although some improvement has been achieved with the application of non-linear modelling techniques that recognize the speed of mean reversion of spot exchange rates to equilibrium values depends crucially upon the size of misalignment. But non-linear modelling has generally not led to a commensurate improvement in the out-ofsample predictive ability of fundamental exchange rate models and this remains generally poor, particularly in the context of point forecasting exercises. ${ }^{25}$

In an effort to improve upon this generally poor track record, much recent research has focused upon market microstructure. Since the seminal work of Evans and Lyons (2001), proponents of this approach have argued that one measure in particular - order flow - may represent the missing link in the process by which dispersed private information is embedded within exchange rates. This process has two stages. First, customers initiate orders with dealers in response to private information that reflects movements in underlying economic

\footnotetext{
${ }^{25}$ See, e.g., Kilian and Taylor (2003). The poor predictive performance of fundamentalsbased exchange rate models does not, however, necessarily imply that such models should be rejected since, as shown by Engel and West (2005), a forward-looking asset price manifests near-random walk behavior if fundamentals are $\mathrm{I}(1)$ and the factor for discounting future fundamentals is near one.
} 
fundamentals. Second, dealers spread the risk assumed from customers during these trades across the interbank market.

The microstructure literature has sparked a lively debate within the academic profession (e.g. Rogoff, 2002). Few disagree with the central hypothesis that order flow is the mechanism by which private information becomes embedded in exchange rates. More disharmony surrounds the assessment of the practical value of this hypothesis. In this paper, we set out to provide a rigorous investigation of the relationship between order flow and subsequent exchange rate returns, using both interdealer and commercially available customer order flow data. In addition, we separated customer order flow into data aggregated across all customers and disaggregated by customer group. In general, we found little evidence that the order flow data that we examined could predict exchange rate movements out of sample. In addition, and in contradiction with theoretical priors, we find widespread evidence of a Granger-causal relationship that runs from exchange rate returns to customer order flow. This result is consistent with evidence presented by Payne and Vitale (2002), Daníelsson, Payne and Luo (2002) and Froot and Ramadorai (2005). We discussed a number of factors that may explain our results. These include market share, issues of sampled databases, pre-filtering and indexation of data and publication lags. No single explanation can provide a complete answer. ${ }^{26}$ This is a possible avenue for future research. But as our study employs customer order flow from two major investment banks as well as interdealer order flow, for a range of exchange rates and sample periods, it seems reasonable to conclude that our results are relatively robust for order flow data commercially available within the market.

It should be stressed that for those participants - typically dealers at major investment banks - who are able to sample order flow at very high frequencies, including on a tick-by-tick, real-time basis, and in a raw, unmanipulated form, order flow data may represent an important, and profitable, source of private information (Bjønnes and Rime, 2001). Indeed, the recent findings of Evans and Lyons (2005a,b; 2006) that customer order flow appears to forecast exchange rates - and even economic fundamentals - seems to indicate this. Therefore, our results do not necessarily invalidate a central hypothesis of the market microstructure literature, namely that customer order flow is indeed the conduit through which fundamental information is imparted into the market.

Neither do our results invalidate the hypothesis that private information and persistent profit opportunities coexist in the foreign exchange market. Indeed, performance data from the currency overlay industry indicate that they do (Baldridge, Meath and Myers, 2000; Hersey and Minnick, 2000; Parker Global,

\footnotetext{
${ }^{26}$ Of the two salient characterstics of the commercially available order flow data, namely that it is published with a lag and that it is filtered into index form, the latter seems the most likely source of loss of information, since the Evans and Lyons (2005a) results suggest that there is considerable Granger-causality beyond normal publication lags running from customer order flow to exchange rates in their unfiltered data.ublication lags.

Another possible reason for our findings - which, given the reputation and size of the institutions involved, seems highly unlikely - is that RBS and JPM customers are dramatically less well informed than the customers initiating the order flows in the Citibank data employed by Evans and Lyons (2005a).
} 
2004). Nor does our research bring into question other findings of the microstructure literature, such as intra-day volatility studies that have achieved a demonstrable ability to predict and practically exploit significant volatility shifts associated with macroeconomic policy announcement events (e.g. Andersen et al 2003; Sager and Taylor, 2004).

But our research does challenge the practical value to the wider market of order flow data commercially available in index form and with publication lags. Indeed, the results presented in this paper show that, except for relatively few, particularly well informed investment bank traders who observe order flow data on a tick-by-tick, real-time and unfiltered basis, knowledge of customer or interdealer order flow cannot help improve the quality of exchange rate forecasting or the profitability of investment portfolio decision-making. ${ }^{27}$

This is interesting from the point of view of foreign exchange market researchers, since it implies that it is not through the actions of traders purchasing and using commecially available order flow data sets that information becomes embedded in the market.

It is also very interesting from the point of view of market participants contemplating whether or not to purchase commercially available order flow data to help them in their investment and trading decisions, since it implies that they would be well advised to bear in mind a simple Latin tag that has served consumers well over the centuries: caveat emptor. ${ }^{28}$

\footnotetext{
${ }^{27}$ Furthermore, the strong contemporaneous correlation between interdealer order flow and exchange rate movements first demonstrated by Evans and Lyons (2002a) may not, it seems, carry over to commercially available customer order data.

28 " caveat emptor [literally., let the purchaser beware], let the purchaser examine the article he is buying before the bargain is completed, so that in case of disappointment after purchase he may not blame the seller." (Oxford English Dictionary Online, http://www.oed.com/).
} 


\section{References}

[1] Anderson, T.G., T. Bollerslev and A. Das (1998), Testing for Market Microstructure Effects in Intraday Volatility: A Reassessment of the Tokyo FX Experiment. Forthcoming, Journal of Finance.

[2] Anderson, T.G., T. Bollerslev, F.X. Diebold and C. Vega (2003), Micro Effects of Macro Announcements: Real-Time Price Discovery in Foreign Exchange. American Economic Review, 93(1), 38-62.

[3] Baldridge, J., B. Meath, and H. Myers (2000), Capturing Alpha Through Active Currency Overlay, Frank Russell Company.

[4] Bank for International Settlements (2005), Triennial Central Bank Survey of Foreign Exchange and Derivatives Market Activity 2004. www.bis.org.

[5] Bates, R.G., M.A.H. Dempster and Y.S. Romahi (2003), Evolutionary Reinforcement Learning in FX Order Book and Order Flow Analysis. IEEE Computational Intelligence for Financial Engineering, 355-62.

[6] Bjønnes, G.H. and D. Rime (2001), Customer Trading and Information in Foreign Exchange Markets. Working Paper \# 4. Stockholm Institute for Financial Research. www.sifr.org.

[7] Bjønnes, G.H. and D. Rime (2005), Dealer Behavior and Trading Systems in Foreign Exchange Markets. Journal of Financial Economics, 75 (3), 571605 .

[8] Bjønnes, G.H., D. Rime and H. O. A. Solheim (2003), Volume and Volatility in the FX-Market: Does it Matter Who You Are? Forthcoming in Exchange Rate Modelling: Where Do We Stand? P. De Grauwe (ed.). MIT Press.

[9] Cai, J., Y.-L. Cheung. R.S.K. Lee and M. Melvin (2001), 'Once-in-aGeneration' Yen Volatility in 1998: Fundamentals, Intervention and Order Flow. Journal of International Money and Finance, 20, 327-47.

[10] Covrig, V. and M. Melvin (2001), Asymmetric Information and Price Discovery in the FX Market: Does Tokyo Know More about the Yen? Journal of Empirical Finance, 9, 271-85.

[11] Daníelsson, J. and R. Payne (2002), Measuring and Explaining Liquidity on an Electronic Limit Order Book: Evidence from Reuters D2000-2, in Bank for International Settlements, CGFS Conference Volume 2: Risk Measurement and Systemic Risk.

[12] Daníelsson, J., R. Payne and J. Luo (2002), Exchange Rate Determination and Inter-Market Order Flow Effects. LSE Financial Markets Group Mimeo.

[13] Diebold, F.X. and R. Mariano (1995), Comparing Predictive Accuracy. Journal of Business and Economic Statistics, 13, 253-62. 
[14] Engel, C. and K.D. West (2005), Exchange Rates and Fundamentals Journal of Political Economy, 113, 485-517

[15] Euromoney (2003), FX Poll 2003. www.euromoney.com/fxpoll2003/fxpollresults.html

[16] Evans, M. and R.K. Lyons (2001), Order Flow and Exchange Rate Dynamics. BIS Papers \#2. http://www.bis.org/publ/bispap02.htm\#pgtop.

[17] Evans, M. and R.K. Lyons (2002a), Order Flow and Exchange Rate Dynamics. Journal of Political Economy, February, 170-80.

[18] Evans, M. and R.K. Lyons (2002b), Informational Integration and FX Trading. Journal of International Money and Finance, 21, 807-31.

[19] Evans, M. and R.K. Lyons (2004), A New Micro Model of Exchange Rate Dynamics, NBER Working Paper \# 10379.

[20] Evans, M. and R.K. Lyons (2005a), The Meese-Rogoff Redux: Micro-Based Exchange Rate Forecasting. Forthcoming American Economic Review, papers and proceedings.

[21] Evans, M. and R.K. Lyons (2005b), Exchange Rate Fundamentals and Order Flow. typescript, U.C. Berkeley

[22] Evans, M. and R.K. Lyons (2006), Understanding Order Flow. Forthcoming, International Journal of Finance and Economics.

[23] Fan, M. and R.K. Lyons (2003), Customer Trades and Extreme Events in Foreign Exchange. In Monetary History, Exchange Rates and Financial Markets: Essays in Honour of Charles Goodhart, Paul Mizen (ed.) Edward Elgar: Northampton, MA, 160-79.

[24] Fisher, P. and R. Hillman (2003), Comments on R.K. Lyons, Explaining and Forecasting Exchange Rates with Order Flows. In Economic Policy Forum: Explaining and Forecasting Exchange Rates With Order Flows. http://www.cepii.fr/anglaisgraph/publications/economieinter/rev96/rev96fischer.pdf.

[25] Frankel, J.A. and A.K. Rose (1996), A Panel Project on Purchasing Power Parity: Mean Reversion Within and Between Countries. Journal of International Economics, 40, 1-2, 209-24.

[26] Froot, K.A. and T. Ramadorai (2002),Currency Returns, Institutional Investor Flows and Exchange-Rate Fundamentals. Journal of Finance, 60(3), $1535-1566$.

[27] Hayek, F. (1945), The Use of Knowledge in Society, American Economic Review, 35, 519-30.

[28] Hersey, B. and J. Minnick (2000), Currency Overlay. Global Pensions. February. 
[29] Ito, T., R.K. Lyons and M.T. Melvin (1998), Is There Private Information in the FX Market? The Tokyo Experiment. Journal of Finance, June, 1111-30.

[30] Jansen, D.J. and J. de Haan (2003), Statements of ECB Officials and their Effect on the Level and Volatility of the Euro-Dollar Exchange Rate. CESifo Working Paper \# 92\%.

[31] JPMorgan (2002), Cross-Border Flow of Funds: a Primer. JPMorgan Global Foreign Exchange Research. http://morganmarkets.jpmorgan.com.

[32] Kilian, L. and M.P. Taylor (2003), Why is it so Difficult to Beat the Random Walk Forecast of Exchange Rates? Journal of International Economics, 60, $85-107$.

[33] Killeen, W.P., R.K. Lyons and M.J. Moore (2006), Fixed Versus Flexible: Lessons from EMS Order Flow. Forthcoming, Journal of International Money and Finance..

[34] Luo, J. (2001), Market Conditions, Order Flow and Exchange Rates (sic.) Determination. London School of Economics Mimeo.

[35] Lyons, R. K. (1995), Tests of Microstructural Hypotheses in the Foreign Exchange Market. Journal of Financial Economics, 39, 321-51.

[36] Lyons, R. K. (1996), Foreign Exchange Volume; Sound and Fury Signifying Nothing? in The Microstructure of Foreign Exchange Markets, J. Frankel et al (eds), University of Chicago Press, 183-201.

[37] Lyons, R.K. (2001), The Microstructure Approach to Exchange Rates. MIT Press.

[38] Lyons, R.K. (2002), Foreign Exchange: Macro Puzzles, Micro Tools. Economic Review, Federal Reserve Bank of San Francisco, 51-69.

[39] Lyons, R.K. (2003), Explaining and Forecasting Exchange Rates with Order Flows. $3^{R D}$ Bank of France Economic Forum. http://www.banquefrance.fr/gb/fondatio/telechar/R_k_lyons.pdf.

[40] Mark, N.C. (1995), Exchange Rates and Fundamentals: Evidence on Long Horizon Predictability. American Economic Review, 85(1), 210-18.

[41] Meese, R.A. and K. Rogoff (1983a), Empirical Exchange Rate Models of the Seventies: Do They Fit Out of Sample? Journal of International Economics, 14, 3-24.

[42] Meese, R.A. and K. Rogoff (1983b), The Out-of-Sample Failure of Empirical Exchange Rate Models: Sampling Error or Misspecification? in Exchange Rate and International Economics, Jacob Frenkel (ed.). Chicago: University of Chicago Press. 
[43] Melvin, M. and L. Wen (2003), The Choice of Direct Dealing or Electronic Brokerage in Foreign Exchange Trading, typescript, Arizona State University.

[44] Mende, A. and L. Menkhoff (2003), Different Counterparties, Different Foreign Exchange Trading? The Perspective of a Median Bank, typescript, University of Hannover.

[45] Newey, W. and K. West (1987). A Simple Positive Semi-Definite, Heteroskedasticity and Autocorrelation Consistent Covariance Matrix, Econometrica, 55, 703-8.

[46] Osler, C.L. (2002), Stop-Loss Orders and Price Cascades in Currency Markets. Federal Reserve Bank of New York Staff Report \# 150.

[47] Osler, C.L. (2003), Currency Orders and Exchange Rate Dynamics: An Explanation for the Predictive Success of Technical Analysis. Journal of Finance, 58, 5, 1791-1820.

[48] Parker Global (2004), Parker FX Index. www.parkerglobal.com.

[49] Payne, R. (2003), Informed Trade in Spot Foreign Exchange Markets: An Empirical Investigation, Journal of International Economics, 61(2), 307-29.

[50] Payne, R. and P. Vitale (2002), A Transaction Level Study of Central Bank Intervention on Exchange Rates, LSE Financial Markets Group Discussion Paper \# 355.

[51] Rime, D. (2001), US Exchange Rates and Currency Flows. Unpublished Mimeo Stockholm Institute for Financial Research. www.sifr.org.

[52] Rogoff, K. (2002), Discussion, in Theoretical Perspective on Euro Liquidity, R. K. Lyons, Economic Policy, 17, 35, 572-97.

[53] Royal Bank of Scotland (2003), FX Flows: Analysis of Customer Flows in the Spot FX Market. RBS.

[54] Sager, M.J. and M.P. Taylor (2004), European Central Bank Governing Council Announcements and the Foreign Exchange Market: A Microstructural Analysis. Journal of International Money and Finance, 23, 7-8, 104351

[55] Sager, M.J. and M.P. Taylor (2006), Under the Microscope: The Structure of the Foreign Exchange Market. Forthcoming, International Journal of Finance and Economics.

[56] Sarno, L. and M. P. Taylor (2002), The Economics of Exchange Rates. Cambridge: Cambridge University Press.

[57] Taylor, M.P. (1995), The Economics of Exchange Rates. Journal of Economic Literature, 33, 13-47. 
[58] Taylor, A.M. and M.P. Taylor (2004), The Purchasing Power Parity Debate, Journal of Economic Perspectives, 18, 135-58. 


\title{
Table 1: Foreign Exchange Market Share Data
}

\author{
Market Share in Customer Orders
}

$\begin{array}{lr}\text { UBS } & 11.53 \% \\ \text { Citigroup } & 9.87 \% \\ \text { Deutsche Bank } & 9.79 \% \\ \text { JPMorgan Chase } & 6.79 \% \\ \text { Goldman Sachs } & 5.56 \% \\ \text { Credit Suisse First Boston } & 4.23 \% \\ \text { HSBC } & 3.89 \% \\ \text { Morgan Stanley } & 3.87 \% \\ \text { Barclays Capital } & 3.84 \% \\ \text { ABN Amro } & 3.63 \% \\ \text { Merrill Lynch } & 2.98 \% \\ \text { Royal Bank of Scotland } & 2.85 \% \\ & \\ \text { Remaining 38 Banks } & 31.17 \% \\ & \\ \text { Source: Euromoney (2003) } & \end{array}$

Notes: The Euromoney survey covers the top 50 banks. Market share data are based on the total volume of foreign exchange business placed annually with each bank. To obtain this figure, respondents to the Euromoney survey estimated the proportion of their total annual foreign exchange dealings placed with their top 10 counterparties. Total business placed with each service provider across all questionnaires received was then divided by total business on all questionnaires ( $\$ 17.1$ trillion) to arrive at a market share figure (Euromoney, 2003). 
Table 2: The Evans and Lyons (2002a) Model Using Evans and Lyons Interdealer Order Flow

\begin{tabular}{lrrlrr}
\multicolumn{3}{c}{ No Publication Lag } & \multicolumn{3}{c}{ With Publication Lag } \\
& & & & & \\
& Mark & \multicolumn{1}{c}{ Yen } & & Mark & Yen \\
$\widehat{\beta}_{1}$ & & & & & \\
& 0.4886 & 2.6694 & $\widehat{\beta}_{1}$ & -0.2067 & 0.7894 \\
& $(0.3476)$ & $(0.9189)$ & & $(0.5865)$ & $(1.2362)$ \\
$\widehat{\beta}_{2}$ & & & & & \\
& 2.1498 & 2.8251 & $\widehat{\beta}_{2}$ & 0.2534 & 0.4460 \\
& $(0.1825)$ & $(0.3539)$ & & $(0.3070)$ & $(0.4770)$ \\
$\overline{R^{2}}$ & & & & & \\
$A I C$ & 0.6353 & 0.4403 & $\overline{R^{2}}$ & -0.0157 & -0.0105 \\
$D W$ & -9.2625 & -8.6185 & $A I C$ & -8.2251 & -8.0415 \\
$J B$ & 1.8631 & 2.2465 & DW & 2.0400 & 2.0666 \\
$A R(1)$ & {$[0.0151]$} & {$[0.8408]$} & JB & {$[0.0000]$} & {$[0.5569]$} \\
$A R C H(1)$ & {$[0.5836]$} & {$[0.1531]$} & $A R(1)$ & {$[0.7126]$} & {$[0.6716]$} \\
& {$[0.0672]$} & {$[0.9295]$} & $A R C H(1)$ & {$[0.9490]$} & {$[0.1730]$}
\end{tabular}

Notes: The regression equation without publication lags is:

$$
\Delta s_{t}=\widehat{\beta}_{1} \Delta\left(i_{t}-i_{t}^{*}\right)+\widehat{\beta}_{2} X_{t}+\eta_{t}
$$

and with publication lags:

$$
\Delta s_{t}=\widehat{\beta}_{1} \Delta\left(i_{t-1}-i_{t-1}^{*}\right)+\widehat{\beta}_{2} X_{t-1}+\eta_{t},
$$

where $\Delta s_{t}$ denotes the one-day exchange rate return, $\Delta\left(i_{t}-i_{t}^{*}\right)$ the one-day change in the one-month interest differential between the domestic and US economies and $X_{t}$ interdealer order flow. Circumflexes denote estimates of the corresponding coefficient. Estimates of $\beta_{1}$ and $\beta_{2}$ and the associated heteroskedastic-robust standard errors, are multiplied by $10,000 . \overline{R^{2}}$ is the degrees-of-freedom-adjusted coefficient of determination; $A I C$ is the Akaike information criterion; $D W$ is the Durbin-Watson statistic; $J B$ is the Jarque-Bera test for residual normality; $A R(1)$ is a lagrange multiplier test statistic for first-order residual serial correlation; $A R C H(1)$ is a lagrange multiplier test statistic for first-order autoregressive conditional heteroskedasticity in the residuals. Figures in square brackets denote marginal significance levels. 
Table 3: Granger-Causality Tests Using Evans and Lyons (2002a) Interdealer Order Flow

$$
\begin{array}{ccc} 
& X_{t} \Longrightarrow \Delta S_{t} & \Delta S_{t} \Longrightarrow X_{t} \\
\text { Mark } & 0.1607 & 0.0084 \\
\text { Yen } & 0.4093 & 0.0818
\end{array}
$$

Notes: Table reports marginal significance levels - p-values - for a $\chi^{2}$ test of joint significance of Granger-causality over 1 to 10 lags. $\Delta S_{t}$ denotes the one-day exchange rate return and $X_{t}$ interdealer order flow. A p-value below $0.05(0.10)$ indicates a significant causal relationship at the $5 \%(10 \%)$ level. 
Table 4: Out-of-Sample, Full information Forecast Errors Using Evans and Lyons (2002a) Interdealer Order Flow

$\begin{array}{ccccc} & \begin{array}{r}\text { Horizon } \\ k\end{array} & \text { Random Walk } & \text { Evans and Lyons } & \text { DM } \\ \text { Mark } & 1 & 0.4332 & 0.2848 & -1.7887 \\ & & & & (0.0736) \\ & 5 & 0.9700 & 0.6248 & -1.5032 \\ & & & & (0.1327) \\ & 10 & 1.5162 & 0.9467 & -1.1958 \\ \text { Yen } & & & (0.2317) \\ & & & & -1.6429 \\ & 1 & 0.4018 & 0.3238 & (0.1004) \\ & & & & -1.3261 \\ & & 0.9513 & 0.6597 & -1.4166 \\ & & & & 0.1565)\end{array}$

Notes: The table reports RMSFEs (multiplied by 100) for dynamic exchange rate forecasts at various horizons derived from a random walk model and the Evans and Lyons (2002a) model, that is:

$$
\widetilde{s}_{t+k}-s_{t}=\sum_{j=1}^{k} \widetilde{\Delta}_{t+j}=\widehat{\beta}_{1} \sum_{j=1}^{k} \Delta\left(i_{t+j}-i_{t+j}^{*}\right)+\widehat{\beta}_{2} \sum_{j=1}^{k} X_{t+j}
$$

where $\widetilde{s}_{t+k}$ denotes the forecast exchange rate, $\Delta\left(i_{t}-i_{t}^{*}\right)$ the one-day change in the one-month interest differential between the domestic and US economies and $X_{t}$ interdealer order flow, and $\widehat{\beta}_{1}$ and $\widehat{\beta}_{2}$ are estimates obtained using data up to time $t$. We use recursive coefficient estimates starting with the first 39 days of the sample. The final column reports DM test statistics of forecast accuracy that indicate the significance of differences in forecast accuracy. A negative statistic indicates that the Evans and Lyons model generates more accurate forecasts than the random walk model. Figures in parentheses indicate the significance of these differences. 
Table 5: Out-of-Sample, Limited Information Forecast Errors Using Evans and Lyons (2002a) Interdealer Order Flow

\begin{tabular}{|c|c|c|c|c|}
\hline & $\begin{array}{l}\text { Horizon } \\
\quad k\end{array}$ & Random Walk & Evans and Lyons & DM \\
\hline \multirow[t]{3}{*}{ Mark } & 1 & 0.4332 & 0.5231 & $\begin{array}{c}2.1681 \\
(0.0301)\end{array}$ \\
\hline & 5 & 0.9700 & 1.8073 & $\begin{array}{c}2.8792 \\
(0.0039)\end{array}$ \\
\hline & 10 & 1.5162 & 2.7752 & $\begin{array}{c}3.4880 \\
(0.0004)\end{array}$ \\
\hline \multirow[t]{3}{*}{ Yen } & 1 & 0.4018 & 0.4191 & $\begin{array}{c}0.3342 \\
(0.7381)\end{array}$ \\
\hline & 5 & 0.9513 & 1.8123 & $\begin{array}{l}13.2997 \\
(0.0000)\end{array}$ \\
\hline & 10 & 1.3883 & 3.2625 & $\begin{array}{c}6.7905 \\
(0.0000)\end{array}$ \\
\hline
\end{tabular}

Notes: The table reports RMSFEs (multiplied by 100) for exchange rate forecasts at various horizons derived from a random walk model and the Evans and Lyons (2002a) model. The latter uses recursive coefficient estimates starting with the first 39 days of the sample and realised values of the forcing variables only at time $t$, that is:

$$
\widetilde{s}_{t+k}-s_{t}=\widehat{\beta}_{1} k \Delta\left(i_{t}-i_{t}^{*}\right)+\widehat{\beta}_{2} k X_{t}
$$

where $\mathrm{k}=1,2, \ldots, 10 . \widetilde{s}_{t+k}$ denotes the forecast value of the exchange rate, $\Delta\left(i_{t}-i_{t}^{*}\right)$ the one day change in the 1-month interest differential between the domestic and US economies and $X_{t}$ interdealer order flow, and $\widehat{\beta}_{1}$ and $\widehat{\beta}_{2}$ are estimates obtained using data up to time $t$. The final column reports DM test statistics of forecast accuracy that indicate the significance of differences in forecast accuracy. A negative statistic indicates that the Evans and Lyons model generates more accurate forecasts than the random walk model. Figures in parentheses indicate the significance of these differences. 
Table 6: In-Sample, Long-Horizon Regressions Using Evans and Lyons (2002a) Interdealer Order Flow

$\begin{array}{cccc} & & & \\ & & & \\ & & & \\ & & & \\ \text { Mark } & & & \\ & & & \\ & 1 & & \\ & 2 & 0.3958 & 0.1992 \\ & 3 & 0.3560 & 0.1780 \\ & 4 & 0.3178 & 0.3756 \\ & 5 & 0.1572 & 0.5000 \\ & 6 & 0.0674 & 0.3406 \\ & 7 & 0.0984 & 0.3418 \\ & 8 & 0.3128 & 0.3472 \\ & 9 & 0.1980 & 0.2226 \\ & 10 & 0.2242 & 0.1516 \\ & & & \\ & 1 & 0.3638 & 0.2636 \\ & 2 & 0.4830 & 0.2570 \\ & 3 & 0.3850 & 0.4844 \\ & 4 & 0.3994 & 0.3744 \\ & 5 & 0.4200 & 0.4282 \\ & 6 & 0.3528 & 0.4324 \\ & 7 & 0.2346 & 0.4826 \\ & 8 & 0.2166 & 0.3564 \\ & 9 & 0.3320 & 0.2962 \\ & 10 & 0.4248 & 0.2376\end{array}$

Notes: The table reports marginal significance levels associated with long-horizon forecasts generated from the Evans and Lyons (2002a) model, that is:

$$
\Delta s_{t+k}=\beta_{1 k} \Delta\left(i_{t}-i_{t}^{*}\right)+\beta_{2 k} X_{t}+\varepsilon_{t+k}
$$

for $k=1,2, \ldots, 10 . \Delta s_{t+k}$ denotes the k-period exchange rate return, $\Delta\left(i_{t}-i_{t}^{*}\right)$ the one day change in the 1-month interest differential between the domestic and US economies and $X_{t}$ interdealer order flow. Marginal significance levels derived from a non-parametric bootstrap that runs 5000 Monte Carlo simulations of a naive random walk model over each forecast horizon, and indicate the significance of observed tstatistics derived from the Evans and Lyons (2002a) model. 
Table 7: The Evans and Lyons (2002a) Model Using JPM FXI Aggregate Customer Data

No Publication Lag

\begin{tabular}{lrr} 
& \multicolumn{1}{c}{ Euro } & \multicolumn{1}{c}{ Yen } \\
$\widehat{\beta}_{1}$ & 0.2736 & 0.0896 \\
& $(0.2867)$ & $(0.2514)$ \\
$\widehat{\beta}_{2}$ & & \\
& -0.0992 & -0.0671 \\
& $(0.0263)$ & $(0.0367)$ \\
$\widehat{\beta}_{3}$ & & \\
& 0.0491 & 0.0765 \\
& $(0.0285)$ & $(0.0346)$ \\
$\bar{R}{ }^{2}$ & & \\
$A I C$ & 0.0219 & 0.0169 \\
$D W$ & -7.3083 & -7.2372 \\
$J B$ & 1.9821 & 2.0220 \\
$A R(1)$ & {$[0.0000]$} & {$[0.0000]$} \\
$A R C H(1)$ & {$[0.8124]$} & {$[0.6614]$} \\
& {$[0.8513]$} & {$[0.0641]$}
\end{tabular}

With Publication Lag

\begin{tabular}{lrr} 
& \multicolumn{1}{c}{ Euro } & \multicolumn{1}{c}{ Yen } \\
$\widehat{\beta}_{1}$ & -0.2792 & -0.2308 \\
& $(0.3101)$ & $(0.2530)$ \\
& & \\
$\widehat{\beta}_{2}$ & 0.0025 & 0.0274 \\
& $(0.0265)$ & $(0.0335)$ \\
$\widehat{\beta}_{3}$ & & \\
& 0.0062 & 0.0045 \\
& $(0.0292)$ & $(0.0346)$ \\
\hline$R^{2}$ & & \\
$A I C$ & -0.0008 & -0.0003 \\
$D W$ & -7.2844 & -7.2206 \\
$J B$ & 1.9511 & 2.0022 \\
$A R(1)$ & {$[0.0000]$} & {$[0.0000]$} \\
$A R C H(1)$ & {$[0.4436]$} & {$[0.9145]$} \\
& {$[0.7933]$} & {$[0.2422]$}
\end{tabular}

(continued......) 
Table 7 (continued.): The Evans and Lyons (2002a) Model Using JPM FXI Aggregate Customer Data

\begin{tabular}{|c|c|c|c|c|c|}
\hline \multicolumn{3}{|c|}{ No Publication Lag } & \multicolumn{3}{|c|}{ With Publication Lag } \\
\hline & Sterling & Swiss franc & & Sterling & Swiss franc \\
\hline$\widehat{\beta}_{1}$ & $\begin{array}{l}-0.1605 \\
(0.1957)\end{array}$ & $\begin{array}{r}0.3541 \\
(0.3105)\end{array}$ & $\widehat{\beta}_{1}$ & $\begin{array}{l}-0.3871 \\
(0.2004)\end{array}$ & $\begin{array}{l}-0.0921 \\
(0.3246)\end{array}$ \\
\hline$\widehat{\beta}_{2}$ & $\begin{array}{l}-0.0329 \\
(0.0211)\end{array}$ & $\begin{array}{l}-0.8697 \\
(0.3080)\end{array}$ & $\widehat{\beta}_{2}$ & $\begin{array}{r}0.0137 \\
(0.0218)\end{array}$ & $\begin{array}{r}0.0240 \\
(0.3003)\end{array}$ \\
\hline$\widehat{\beta}_{3}$ & $\begin{array}{r}0.0867 \\
(0.0222)\end{array}$ & $\begin{array}{r}0.9176 \\
(0.3027)\end{array}$ & $\widehat{\beta}_{3}$ & $\begin{array}{r}0.0388 \\
(0.0216)\end{array}$ & $\begin{array}{r}0.2487 \\
(0.2963)\end{array}$ \\
\hline$\overline{R^{2}}$ & 0.0208 & 0.0233 & $\overline{R^{2}}$ & 0.0050 & -0.0010 \\
\hline$A I C$ & -7.9159 & -7.2610 & $A I C$ & -7.8993 & -7.2355 \\
\hline$D W$ & 1.9964 & 2.0226 & $D W$ & 1.9804 & 2.0030 \\
\hline$J B$ & {$[0.0000]$} & {$[0.0000]$} & $J B$ & {$[0.0000]$} & {$[0.0000]$} \\
\hline$A R(1)$ & {$[0.9716]$} & {$[0.6419]$} & $A R(1)$ & {$[0.7532]$} & {$[0.8529]$} \\
\hline$A R C H(1)$ & {$[0.8205]$} & {$[0.5415]$} & $A R C H(1)$ & {$[0.7455]$} & {$[0.4307]$} \\
\hline
\end{tabular}

Notes: The regression equation without publication lags is:

$$
\Delta s_{t}=\widehat{\beta}_{1} \Delta\left(i_{t}-i_{t}^{*}\right)+\widehat{\beta}_{2} X_{t}^{D O M}+\widehat{\beta}_{3} X_{t}^{U S}+\eta_{t}
$$

and with publication lags:

$$
\Delta s_{t}=\widehat{\beta}_{1} \Delta\left(i_{t-1}-i_{t-1}^{*}\right)+\widehat{\beta}_{2} X_{t-1}^{D O M}+\widehat{\beta}_{3} X_{t-1}^{U S}+\eta_{t},
$$

where $\Delta s_{t}$ denotes the one day exchange rate return, $\Delta\left(i_{t}-i_{t}^{*}\right)$ the one day change in the 1-month interest differential between the domestic and US economies, $X_{t}^{D O M}$ is aggregate customer order flow into the domestic currency and $X_{t}^{U S}$ is aggregate customer order flow into the dollar, both transacted with JPM as measured by the FXI. Circumflexes denote estimates of the corresponding coefficient. Estimates of $\beta_{1}, \beta_{2}$ and $\beta_{3}$, and associated heteroskedastic-robust standard errors, are multiplied by $10,000 . \overline{R^{2}}$ is the degrees-of-freedom-adjusted coefficient of determination; $A I C$ is the Akaike information criterion; $D W$ is the Durbin-Watson statistic; $J B$ is the Jarque-Bera test for residual normality; $A R(1)$ is a lagrange multiplier test statistic for first-order residual serial correlation; $A R C H(1)$ is a lagrange multiplier test statistic for first-order autoregressive conditional heteroskedasticity in the residuals. Figures in square brackets denote marginal significance levels. 
Table 8: Granger-Causality Tests Using JPM FXI Aggregate Customer Data

\author{
Null Hypothesis P-Value
}

Euro

$$
\begin{array}{cc}
X_{t}^{D O M} \Longrightarrow \Delta S_{t} & 0.6863 \\
\Delta S_{t} \Longrightarrow X_{t}^{D O M} & 0.0000 \\
& \\
X_{t}^{U S} \Longrightarrow \Delta S_{t} & 0.4640 \\
\Delta S_{t} \Longrightarrow X_{t}^{U S} & 0.0000
\end{array}
$$

Yen

$$
\begin{array}{cc}
X_{t}^{D O M} \Longrightarrow \Delta S_{t} & 0.0108 \\
\Delta S_{t} \Longrightarrow X_{t}^{D O M} & 0.0000 \\
& \\
X_{t}^{U S} \Longrightarrow \Delta S_{t} & 0.2525 \\
\Delta S_{t} \Longrightarrow X_{t}^{U S} & 0.0000
\end{array}
$$

Sterling $\quad X_{t}^{D O M} \Longrightarrow \Delta S_{t} \quad 0.2842$

$$
\Delta S_{t} \Longrightarrow X_{t}^{D O M} \quad 0.0024
$$$$
X_{t}^{U S} \Longrightarrow \Delta S_{t} \quad 0.1302
$$$$
\Delta S_{t} \Longrightarrow X_{t}^{U S} \quad 0.0000
$$

Swiss franc $X_{t}^{D O M} \Longrightarrow \Delta S_{t} \quad 0.5959$

$$
\begin{array}{cc}
\Delta S_{t} \Longrightarrow X_{t}^{D O M} & 0.0000 \\
X_{t}^{U S} \Longrightarrow \Delta S_{t} & 0.5151 \\
\Delta S_{t} \Longrightarrow X_{t}^{U S} & 0.0000
\end{array}
$$

Notes: Table reports marginal significance levels - p-values-for a $\chi^{2}$ test of joint significance of Granger-causality over 1 to 10 lags. $\Delta S_{t}$ denotes the one day exchange rate return, $X_{t}^{D O M}$ is aggregate customer order flow into the domestic currency and $X_{t}^{U S}$ is aggregate customer order flow into the dollar, both transacted with JPM as measured by the FXI. A p-value below $0.05(0.10)$ indicates a significant causal relationship at the $5 \%(10 \%)$ level. 
Table 9: Out-of-Sample, Full Information Forecast Errors Using JPM FXI Aggregate Customer Data

\begin{tabular}{|c|c|c|c|c|}
\hline & Horizon & Random Walk & Evans and Lyons & DM \\
\hline \multirow{4}{*}{ Euro } & 1 & 0.6470 & 0.6418 & -17453 \\
\hline & & & & $(0.0809)$ \\
\hline & 5 & 1.4726 & 1.4282 & -2.3614 \\
\hline & 10 & 2.1156 & 2.0258 & $\begin{array}{r}-2.2163 \\
(0.0266)\end{array}$ \\
\hline \multirow[t]{4}{*}{ Yen } & 1 & 0.6146 & 0.6152 & 0.1500 \\
\hline & & 12170 & 12054 & $(0.8807)$ \\
\hline & 5 & 1.3170 & 1.2954 & $\begin{array}{l}-0.6817 \\
(0.4953)\end{array}$ \\
\hline & 10 & 1.8842 & 1.8103 & $\begin{array}{c}-1.2379 \\
(0.2157)\end{array}$ \\
\hline \multirow[t]{3}{*}{ Sterling } & 1 & 0.4763 & 0.4724 & $\begin{array}{r}-1.6527 \\
(0.0983)\end{array}$ \\
\hline & 5 & 1.0725 & 1.0228 & $\begin{array}{l}-2.8603 \\
(0.0042)\end{array}$ \\
\hline & 10 & 1.5303 & 1.4034 & $\begin{array}{l}-3.3240 \\
(0.0008)\end{array}$ \\
\hline \multirow[t]{3}{*}{ Swiss franc } & 1 & 0.6560 & 0.6527 & -0.8871 \\
\hline & 5 & 1.4626 & 1.4148 & -1.8867 \\
\hline & 10 & 2.0928 & 1.9786 & $\begin{array}{c}-2.0862 \\
(0.0369)\end{array}$ \\
\hline
\end{tabular}

Notes: The table reports RMSFEs (multiplied by 100) for forecasts at various horizons derived from a random walk model from dynamic forecasts generated using the Evans and Lyons (2002a) model using JPM FXI order flow, that is:

$$
\widetilde{s}_{t+k}-s_{t}=\sum_{j=1}^{k} \widetilde{\Delta s_{t+j}}=\widehat{\beta}_{1} \sum_{j=1}^{k} \Delta\left(i_{t+j}-i_{t+j}^{*}\right)+\widehat{\beta}_{2} \sum_{j=1}^{k} X_{t+j}^{D O M}+\widehat{\beta}_{3} \sum_{j=1}^{k} X_{t+j}^{U S}
$$

where $\widetilde{s}_{t+k}$ denotes the forecast exchange rate, $\Delta\left(i_{t}-i_{t}^{*}\right)$ the one day change in the 1-month interest differential between the domestic and US economies. $X_{t}^{D O M}$ is aggregate customer order flow into the domestic currency and $X_{t}^{U S}$ is aggregate 
customer order flow into the dollar, both transacted with JPM as measured by the FXI. $\widehat{\beta}_{1}, \widehat{\beta}_{2}$ and $\widehat{\beta}_{3}$ are estimates obtained using data up to time $t$. We use recursive coefficient estimates starting with the first 200 days of the sample. The final column reports DM test statistics of forecast accuracy that indicate the significance of differences in forecast accuracy. A negative statistic indicates that the Evans and Lyons model generates more accurate forecasts than the random walk model. Figures in parentheses indicate the significance of these differences. 
Table 10: Out-of-Sample, Limited Information Forecast Errors Using JPM FXI Aggregate Customer Data

\begin{tabular}{|c|c|c|c|c|}
\hline & $\begin{array}{l}\text { Horizon } \\
k\end{array}$ & Random Walk & Evans and Lyons & $\mathrm{DM}$ \\
\hline \multirow[t]{3}{*}{ Euro } & 1 & 0.6470 & 0.6547 & 2.7860 \\
\hline & 5 & 1.4726 & 1.5597 & $\begin{array}{r}(.0053) \\
3.3982 \\
(0.0006)\end{array}$ \\
\hline & 10 & 2.1156 & 2.3406 & $\begin{array}{r}4.1811 \\
(0.0000)\end{array}$ \\
\hline \multirow[t]{3}{*}{ Yen } & 1 & 0.6146 & 0.6259 & $\begin{array}{r}3.1035 \\
(0.0019)\end{array}$ \\
\hline & 5 & 1.3170 & 1.4678 & $\begin{array}{r}3.9389 \\
(0.0000)\end{array}$ \\
\hline & 10 & 1.8804 & 2.2768 & $\begin{array}{r}4.9327 \\
(0.0000)\end{array}$ \\
\hline \multirow[t]{3}{*}{ Sterling } & 1 & 0.4763 & 0.4769 & $\begin{array}{r}0.2570 \\
(0.7971)\end{array}$ \\
\hline & 5 & 1.0725 & 1.0888 & $\begin{array}{r}0.8232 \\
(0.4103)\end{array}$ \\
\hline & 10 & 1.5303 & 1.6232 & $\begin{array}{r}2.1234 \\
(0.0337)\end{array}$ \\
\hline \multirow[t]{3}{*}{ Swiss franc } & 1 & 0.6560 & 0.6631 & $\begin{array}{r}1.8351 \\
(0.0664)\end{array}$ \\
\hline & 5 & 1.4626 & 1.5678 & $\begin{array}{r}3.4276 \\
(0.0006)\end{array}$ \\
\hline & 10 & 2.0928 & 2.3887 & $\begin{array}{r}4.8372 \\
(0.0000)\end{array}$ \\
\hline
\end{tabular}

Notes: The table reports RMSFEs (multiplied by 100) for exchange rate forecasts at various horizons derived from a random walk model and the Evans and Lyons (2002a) model using JPM FXI order flow. The latter uses recursive coefficient estimates starting with the first 200 days of the sample and realised values of the forcing variables, that is:

$$
\widetilde{s}_{t+k}-s_{t}=\widehat{\beta}_{1} k \Delta\left(i_{t}-i_{t}^{*}\right)+\widehat{\beta}_{2} k X_{t}^{D O M}+\widehat{\beta}_{3} k X_{t}^{U S}
$$

where $\mathrm{k}=1,2, \ldots, 10 . \widetilde{s}_{t+k}$ denotes the forecast value of the exchange rate, $\Delta\left(i_{t}-i_{t}^{*}\right)$ the one day change in the 1-month interest differential between the domestic and US 
economies, $X_{t}^{D O M}$ is aggregate customer order flow into the domestic currency and $X_{t}^{U S}$ is aggregate customer order flow into the dollar, both transacted with JPM as measured by the FXI. $\widehat{\beta}_{1}, \widehat{\beta}_{2}$ and $\widehat{\beta}_{3}$ are estimates obtained using data up to time $t$. We use recursive coefficient estimates starting with the initial 200 days of the sample. A negative DM test statistic indicates that Evans and Lyons forecasts are more accurate than a random walk. Figures in parentheses indicate the significance of these differences. 
Table 11: In-Sample, Long-Horizon Forecasts Using JPM FXI Aggregate Customer Data

$\begin{array}{cccccc} & \begin{array}{c}\text { Horizon } \\ k\end{array} & \widehat{\beta}_{1 k} & \widehat{\beta}_{2 k} & \widehat{\beta}_{3 k} & \text { Joint } \\ & & & & & \\ \text { Euro } & 1 & 0.1896 & 0.4470 & 0.4174 & 0.8420 \\ & 2 & 0.1728 & 0.3432 & 0.4864 & 0.7890 \\ & 3 & 0.1178 & 0.2502 & 0.4732 & 0.5844 \\ & 4 & 0.0274 & 0.1850 & 0.4956 & 0.2016 \\ & 5 & 0.1978 & 0.1948 & 0.4744 & 0.6686 \\ & 6 & 0.1700 & 0.2318 & 0.4670 & 0.6344 \\ & 7 & 0.4372 & 0.2906 & 0.4004 & 0.8856 \\ & 8 & 0.3466 & 0.3410 & 0.3852 & 0.8830 \\ & 9 & 0.4706 & 0.3566 & 0.3964 & 0.9500 \\ & 10 & 0.2944 & 0.3600 & 0.3690 & 0.8554 \\ \text { Yen } & & & & & \\ & 1 & 0.1886 & 0.2266 & 0.4486 & 0.6732 \\ & 2 & 0.2220 & 0.1938 & 0.4568 & 0.6562 \\ & 3 & 0.3428 & 0.0744 & 0.3654 & 0.3664 \\ 4 & 0.3532 & 0.0746 & 0.3098 & 0.3982 \\ & 5 & 0.2082 & 0.0618 & 0.3214 & 0.2808 \\ & 6 & 0.4906 & 0.0440 & 0.2594 & 0.3058 \\ & 7 & 0.4526 & 0.0362 & 0.2518 & 0.2748 \\ & 8 & 0.4142 & 0.0440 & 0.3002 & 0.2878 \\ 9 & 0.3336 & 0.0398 & 0.3432 & 0.2392 \\ & 10 & 0.1762 & 0.0346 & 0.3710 & 0.1658\end{array}$

(continued...) 
Table 11 (cont.): In-Sample, Long-Horizon Forecasts Using JPM Aggregate FXI Customer Data

$\begin{array}{lccccc} & \begin{array}{c}\text { Horizon } \\ \text { Sterling }\end{array} & \widehat{\beta}_{1 k} & \widehat{\beta}_{2 k} & \widehat{\beta}_{3 k} & \text { Joint } \\ & 1 & & & & \\ & 2 & 0.0224 & 0.2630 & 0.0326 & 0.0712 \\ & 3 & 0.0642 & 0.2668 & 0.0212 & 0.0992 \\ & 4 & 0.0252 & 0.1872 & 0.0116 & 0.0360 \\ & 5 & 0.0412 & 0.1756 & 0.0106 & 0.0662 \\ & 6 & 0.0844 & 0.1374 & 0.0042 & 0.0590 \\ & 7 & 0.1356 & 0.0798 & 0.0086 & 0.0668 \\ & 8 & 0.1054 & 0.0634 & 0.0158 & 0.1034 \\ & 9 & 0.1110 & 0.0780 & 0.0348 & 0.1794 \\ & 10 & 0.0318 & 0.0880 & 0.0640 & 0.1266 \\ & & & & & \\ & 1 & 0.3858 & 0.4660 & 0.2202 & 0.8322 \\ & 2 & 0.0686 & 0.1804 & 0.1600 & 0.3342 \\ & 3 & 0.0748 & 0.1306 & 0.2066 & 0.3084 \\ & 4 & 0.1526 & 0.1504 & 0.2358 & 0.4374 \\ & 5 & 0.3088 & 0.1026 & 0.2346 & 0.5156 \\ & 6 & 0.2854 & 0.0776 & 0.2814 & 0.4700 \\ & 7 & 0.4800 & 0.0686 & 0.3692 & 0.4992 \\ & 8 & 0.3504 & 0.0718 & 0.3936 & 0.4754 \\ 9 & 0.4546 & 0.0560 & 0.3778 & 0.4484 \\ & 10 & 0.4072 & 0.0660 & 0.4222 & 0.4616\end{array}$

Notes: The table reports marginal significance levels associated with long-horizon regressions generated from the Evans and Lyons (2002a) model using JPM FXI order flow, that is:

$$
\Delta s_{t+k}=\beta_{1 k} \Delta\left(i_{t}-i_{t}^{*}\right)+\beta_{2 k} X_{t}^{D O M}+\beta_{3 k} X_{t}^{U S}+\varepsilon_{t+k}
$$

for $k=1,2, \ldots, 10 . \Delta s_{t+k}$ denotes the k-period exchange rate return, $\Delta\left(i_{t}-i_{t}^{*}\right)$ the one day change in the 1-month interest differential between the domestic and US economies. $X_{t}^{D O M}$ is aggregate customer order flow into the domestic currency and $X_{t}^{U S}$ is aggregate customer order flow into the dollar, both transacted with JPM as measured by the FXI. Marginal significance levels derived from non-parametric bootstrap that runs 5000 Monte Carlo simulations of a naive random walk model over each forecast horizon from $\mathrm{k}=1$ to 10 . Joint is a $\chi^{2}$ test of joint coefficient significance. 
Table 12: The Evans and Lyons (2002a) Model Using RBS Aggregate FFI Customer Data

\begin{tabular}{|c|c|c|c|c|c|}
\hline \multicolumn{3}{|c|}{ No Publication Lag } & \multicolumn{3}{|c|}{ With Publication Lag } \\
\hline & Euro & Yen & & Euro & Yen \\
\hline$\widehat{\beta}_{1}$ & $\begin{array}{l}-0.4796 \\
(0.7133)\end{array}$ & $\begin{array}{c}-0.9152 \\
(0.8989)\end{array}$ & $\widehat{\beta}_{1}$ & $\begin{array}{c}-0.5022 \\
(0.7092)\end{array}$ & $\begin{array}{r}0.6539 \\
(0.9291)\end{array}$ \\
\hline$\widehat{\beta}_{2}$ & $\begin{array}{r}-64.3671 \\
(142.8075)\end{array}$ & $\begin{array}{r}488.9440 \\
(155.0039)\end{array}$ & $\widehat{\beta}_{2}$ & $\begin{array}{l}-155.7218 \\
(142.9603)\end{array}$ & $\begin{array}{r}99.8080 \\
(157.6374)\end{array}$ \\
\hline$\overline{R^{2}}$ & -0.0138 & 0.0217 & $\overline{R^{2}}$ & -0.0111 & -0.0053 \\
\hline$A I C$ & -7.5531 & -7.4539 & $A I C$ & -7.5533 & -7.4268 \\
\hline$D W$ & 2.0025 & 2.0985 & $D W$ & 2.0082 & 2.0524 \\
\hline D & {$[0.0002]$} & {$[0.0000]$} & $J B$ & {$[0.0004]$} & {$[0.0000]$} \\
\hline & {$[0.9843]$} & {$[0.3195]$} & $A R(1)$ & [0.9258] & {$[0.6051]$} \\
\hline$A R C H(1)$ & {$[0.7691]$} & {$[0.5140]$} & $A R C H(1)$ & {$[0.8339]$} & {$[0.4737]$} \\
\hline
\end{tabular}

(continued...) 


\section{Table 12 (Cont.): Evans and Lyons (2002a) Model Applied to RBS Aggregate FFI Customer Data}

\begin{tabular}{lrrlrr}
\multicolumn{3}{c}{ No Publication Lag } & \multicolumn{3}{c}{ With Publication Lag } \\
& & & & & \\
& & & & & \\
& & & & & \\
$\widehat{\beta}_{1}$ & -0.3944 & 0.1752 & $\widehat{\beta}_{1}$ & 0.1743 & -0.3008 \\
& $(0.4063)$ & $(0.7166)$ & & $(0.4067)$ & $(0.7229)$ \\
& & & & & \\
$\widehat{\beta}_{2}$ & -215.0122 & 157.1606 & $\widehat{\beta}_{2}$ & -129.8212 & -63.3646 \\
& $(121.6097)$ & $(86.9848)$ & & $(121.4232)$ & $(87.0259)$ \\
& & & & & \\
$\overline{R^{2}}$ & 0.0626 & -0.0020 & $\bar{R}$ & 0.0547 & -0.0089 \\
$A I C$ & -8.0097 & -7.3644 & $A I C$ & -8.0114 & -7.3549 \\
$D W$ & 1.9510 & 2.0039 & $D W$ & 1.9352 & 2.0026 \\
$J B$ & {$[0.0000]$} & {$[0.0000]$} & $J B$ & {$[0.0000]$} & {$[0.0000]$} \\
$A R(1)$ & {$[0.7297]$} & {$[0.9682]$} & $A R(1)$ & {$[0.5735]$} & {$[0.9604]$} \\
$A R C H(1)$ & {$[0.4884]$} & {$[0.9776]$} & $A R C H(1)$ & {$[0.4671]$} & {$[0.8855]$}
\end{tabular}

Notes: The regression equation without publication lags is:

$$
\Delta s_{t}=\widehat{\beta}_{1} \Delta\left(i_{t}-i_{t}^{*}\right)+\widehat{\beta}_{2} X_{t}+\eta_{t}
$$

and with publication lags:

$$
\Delta s_{t}=\widehat{\beta}_{1} \Delta\left(i_{t-1}-i_{t-1}^{*}\right)+\widehat{\beta}_{2} X_{t-1}+\eta_{t},
$$

where $\Delta s_{t}$ denotes the one day exchange rate return, $\Delta\left(i_{t}-i_{t}^{*}\right)$ the one day change in the 1-month interest differential between the domestic and US economies and $X_{t}$ aggregate customer order flow transacted with RBS as measured by the FFI. Circumflexes denote estimates of the corresponding coefficient. Estimates of $\beta_{1}$ and $\beta_{2}$, and associated heteroskedastic-robust standard errors, are multiplied by $10,000 . \overline{R^{2}}$ is the degrees-of-freedom-adjusted coefficient of determination; $A I C$ is the Akaike information criterion; $D W$ is the Durbin-Watson statistic; $J B$ is the Jarque-Bera test for residual normality; $A R(1)$ is a lagrange multiplier test statistic for first-order residual serial correlation; $A R C H(1)$ is a lagrange multiplier test statistic for first-order autoregressive conditional heteroskedasticity in the residuals. Figures in square brackets denote marginal significance levels. 
Table 13: Granger-Causality Tests Using RBS Aggregate FFI Customer Data

\author{
Null Hypothesis P-Value
}

$\begin{array}{cll}\text { Euro } & X_{t} \Longrightarrow \Delta S_{t} & 0.5468 \\ & \Delta S_{t} \Longrightarrow X_{t} & 0.2417 \\ \text { Yen } & X_{t} \Longrightarrow \Delta S_{t} & 0.2603 \\ & \Delta S_{t} \Longrightarrow X_{t} & 0.0000\end{array}$

Sterling $\quad X_{t} \Longrightarrow \Delta S_{t} \quad 0.2135$

$\Delta S_{t} \Longrightarrow X_{t} \quad 0.3024$

Swiss franc $\quad X_{t} \Longrightarrow \Delta S_{t} \quad 0.3733$

$\Delta S_{t} \Longrightarrow X_{t} \quad 0.0624$

Notes: Table reports marginal significance levels $-\mathrm{p}$-values - for a $\chi^{2}$ test of joint significance of Granger-causality over 1 to 10 lags. $\Delta S_{t}$ denotes the one day exchange rate return and $X_{t}$ aggregate customer order flow transacted with RBS, as measured by the FFI. A p-value below 0.05 (0.10) indicates a significant causal relationship at the $5 \%(10 \%)$ level. 
Table 14: Out-of-Sample, Full-Information Forecast Errors Using RBS Aggregate FFI Customer Data

\begin{tabular}{|c|c|c|c|c|}
\hline & Horizon & Random Walk & Evans and Lyons & $\mathrm{DM}$ \\
\hline \multirow[t]{4}{*}{ Euro } & 1 & 0.5596 & 0.5606 & 0.6456 \\
\hline & & & & $(0.5184)$ \\
\hline & 5 & 1.3722 & 1.3694 & $\begin{array}{l}-0.3911 \\
(0.6957)\end{array}$ \\
\hline & 10 & 1.9256 & 1.9206 & $\begin{array}{c}-0.3324 \\
(0.7395)\end{array}$ \\
\hline \multirow[t]{3}{*}{ Yen } & 1 & 0.5986 & 0.5898 & $\begin{array}{c}-1.5394 \\
(0.1237)\end{array}$ \\
\hline & 5 & 1.3230 & 1.2592 & $\begin{array}{l}-2.4243 \\
(0.0153)\end{array}$ \\
\hline & 10 & 1.7941 & 1.6724 & $\begin{array}{l}-2.8647 \\
(0.0041)\end{array}$ \\
\hline \multirow[t]{3}{*}{ Sterling } & 1 & 0.4854 & 0.4861 & $\begin{array}{r}0.1812 \\
(0.8561)\end{array}$ \\
\hline & 5 & 1.0793 & 1.0921 & $\begin{array}{r}1.1403 \\
(0.2541)\end{array}$ \\
\hline & 10 & 1.4949 & 1.5183 & $\begin{array}{r}1.1601 \\
(0.2459)\end{array}$ \\
\hline \multirow[t]{3}{*}{ Swiss franc } & 1 & 0.6223 & 0.6239 & $\begin{array}{r}0.3895 \\
(0.6968)\end{array}$ \\
\hline & 5 & 1.4639 & 1.4483 & $\begin{array}{r}-0.8500 \\
(0.3952)\end{array}$ \\
\hline & 10 & 2.0820 & 2.0572 & $\begin{array}{c}-0.6411 \\
(0.5214)\end{array}$ \\
\hline
\end{tabular}

Notes: The table reports RMSFEs (multiplied by 100) for forecasts at various horizons derived from a random walk model and the Evans and Lyons (2002a) model using RBS FFI order flow, that is:

$$
\widetilde{s}_{t+k}-s_{t}=\sum_{j=1}^{k} \widetilde{\Delta s_{t+j}}=\widehat{\beta}_{1} \sum_{j=1}^{k} \Delta\left(i_{t+j}-i_{t+j}^{*}\right)+\widehat{\beta}_{2} \sum_{j=1}^{k} X_{t+j}
$$

where $\widetilde{s}_{t+k}$ denotes the forecast exchange rate, $\Delta\left(i_{t}-i_{t}^{*}\right)$ the one day change in the 1-month interest differential between the domestic and US economies and $X_{t}$ aggregate customer order flow transacted with RBS, as measured by the FFI. $\widehat{\beta}_{1}$ and $\widehat{\beta}_{2}$ 
are estimates obtained using data up to time $t$. We use recursive coefficient estimates starting with the first 200 days of the sample. The final column reports DM test statistics of forecast accuracy that indicate the significance of differences in forecast accuracy. A negative statistic indicates that the Evans and Lyons model generates more accurate forecasts than the random walk model. Figures in parentheses indicate the significance of these differences. 
Table 15: Out-of-Sample, Limited-Information Forecast Errors Using RBS Aggregate FFI Customer Data

\begin{tabular}{|c|c|c|c|c|}
\hline & Horizon & Random Walk & Evans and Lyons & $\mathrm{DM}$ \\
\hline \multirow[t]{3}{*}{ Euro } & 1 Day & 0.5596 & 0.5581 & $\begin{array}{r}-0.8476 \\
(0.3966)\end{array}$ \\
\hline & 1 Week & 1.3722 & 1.3857 & $\begin{array}{r}(0.3966) \\
1.1816 \\
(0.2373)\end{array}$ \\
\hline & 2 Weeks & 1.9256 & 1.9635 & $\begin{array}{r}1.3452 \\
(0.1785)\end{array}$ \\
\hline \multirow[t]{3}{*}{ Yen } & 1 Day & 0.5986 & 0.5986 & $\begin{array}{r}0.8382 \\
(0.4019)\end{array}$ \\
\hline & 1 Week & 1.3230 & 1.4056 & $\begin{array}{r}2.3391 \\
(0.0193)\end{array}$ \\
\hline & 2 Weeks & 1.7941 & 2.0368 & $\begin{array}{r}4.3961 \\
(0.0000)\end{array}$ \\
\hline \multirow[t]{3}{*}{ Sterling } & 1 Day & 0.4854 & 0.4875 & $\begin{array}{r}0.6456 \\
(0.5184)\end{array}$ \\
\hline & 1 Week & 1.0793 & 1.1164 & $\begin{array}{r}2.2430 \\
(0.0248)\end{array}$ \\
\hline & 2 Weeks & 1.4949 & 1.6064 & $\begin{array}{r}3.6624 \\
(0.0002)\end{array}$ \\
\hline \multirow[t]{3}{*}{ Swiss franc } & 1 Day & 0.6223 & 0.6231 & $\begin{array}{r}0.2805 \\
(0.7790)\end{array}$ \\
\hline & 1 Week & 1.4639 & 1.4712 & $\begin{array}{r}0.1778 \\
(0.8588)\end{array}$ \\
\hline & 2 Weeks & 2.0820 & 2.1330 & $\begin{array}{r}1.4781 \\
(0.1393)\end{array}$ \\
\hline
\end{tabular}

Notes: The table reports RMSFEs (multiplied by 100) for exchange rate forecasts at various horizons derived from a random walk model and the Evans and Lyons (2002a) model using RBS FFI order flow. The latter uses recursive coefficient estimates starting with the first 200 days of the sample and realised values of the forcing variables, that is:

$$
\widetilde{s}_{t+k}-s_{t}=\widehat{\beta}_{1} k \Delta\left(i_{t}-i_{t}^{*}\right)+\widehat{\beta}_{2} k X_{t}
$$

where $\widetilde{s}_{t+k}$ is the forecast exchange rate, $\Delta\left(i_{t}-i_{t}^{*}\right)$ the one-day change in the onemonth interest differential between the domestic and US economies and $X_{t}$ aggregate customer order flow transacted with RBS, as measured by the FFI. $\widehat{\beta}_{1}$ and $\widehat{\beta}_{2}$ are 
estimates obtained using data up to time $t$. We use recursive coefficient estimates starting with the first 200 days of the sample. A negative DM test statistic indicates that Evans and Lyons forecasts are more accurate than a random walk. Figures in parentheses indicate the significance of these differences. 
Table 16: In-Sample Long-Horizon Forecasts Using RBS Aggregate FFI Customer Data

$\begin{array}{ccccc} & \begin{array}{c}\text { Horizon } \\ \text { Euro }\end{array} & \widehat{\beta}_{1 k} & \widehat{\beta}_{2 k} & \text { Joint } \\ & k & & & \\ & 1 & 0.2256 & 0.1686 & 0.4438 \\ & 2 & 0.3966 & 0.0524 & 0.2430 \\ & 3 & 0.4796 & 0.4700 & 0.9546 \\ & 4 & 0.4418 & 0.2518 & 0.6746 \\ & 5 & 0.3476 & 0.1734 & 0.4776 \\ & 6 & 0.3870 & 0.1000 & 0.3159 \\ & 7 & 0.2456 & 0.1406 & 0.3608 \\ & 8 & 0.2708 & 0.1014 & 0.3004 \\ & 9 & 0.1314 & 0.0878 & 0.1624 \\ & 10 & 0.0938 & 0.0886 & 0.1397 \\ & & & & \\ & 1 & 0.3038 & 0.2418 & 0.7108 \\ & 2 & 0.3176 & 0.2666 & 0.7606 \\ & 3 & 0.2912 & 0.0828 & 0.3972 \\ 4 & 0.4484 & 0.0716 & 0.4158 \\ & 5 & 0.4560 & 0.1306 & 0.5567 \\ & 6 & 0.4682 & 0.1382 & 0.6117 \\ & 7 & 0.3860 & 0.1230 & 0.5703 \\ & 8 & 0.2708 & 0.1474 & 0.5286 \\ 9 & 0.0720 & 0.2850 & 0.3735 \\ & 10 & 0.2814 & 0.0522 & 0.2402\end{array}$

(Continued...) 
Table 16 (Cont.): In-Sample, Long-Horizon Forecasts Using RBS Aggregate FFI Customer Data

$\begin{array}{lcccc} & \begin{array}{c}\text { Horizon } \\ k\end{array} & \widehat{\beta}_{1 k} & \widehat{\beta}_{2 k} & \text { Joint } \\ \text { Sterling } & 1 & & & \\ & 2 & 0.3180 & 0.1160 & 0.4994 \\ & 3 & 0.4458 & 0.3354 & 0.9080 \\ & 4 & 0.22362 & 0.1678 & 0.5756 \\ & 5 & 0.2094 & 0.0962 & 0.4042 \\ & 6 & 0.1820 & 0.1832 & 0.5104 \\ & 7 & 0.2052 & 0.3484 & 0.6553 \\ & 8 & 0.1500 & 0.4826 & 0.5372 \\ & 9 & 0.2040 & 0.4196 & 0.6706 \\ & 10 & 0.1068 & 0.3104 & 0.3797 \\ & & & & \\ & 1 & 0.3458 & 0.1934 & 0.7198 \\ & 2 & 0.3058 & 0.5822 & 0.9116 \\ & 3 & 0.1838 & 0.3296 & 0.5388 \\ & 4 & 0.3048 & 0.3540 & 0.7088 \\ & 5 & 0.2284 & 0.1430 & 0.3274 \\ & 6 & 0.2148 & 0.1996 & 0.4342 \\ & 7 & 0.2030 & 0.2362 & 0.4970 \\ & 8 & 0.1608 & 0.2282 & 0.3874 \\ 9 & 0.2480 & 0.3526 & 0.6126 \\ & 9 & 0.3226 & 0.4020 & 0.7123\end{array}$

Notes: The table reports marginal significance levels associated with long horizon forecasts generated from the Evans and Lyons (2002a) model using RBS FFI order flow, that is:

$$
\Delta s_{t+k}=\beta_{1 k} \Delta\left(i_{t}-i_{t}^{*}\right)+\beta_{2 k} X_{t}+\varepsilon_{t+k}
$$

for $k=1,2, \ldots, 10 . \Delta s_{t+k}$ denotes the k-period exchange rate return, $\Delta\left(i_{t}-i_{t}^{*}\right)$ the one day change in the 1-month interest differential between the domestic and US economies and $X_{t}$ aggregate customer order flow transacted with RBS, as measured by the FFI. Marginal significance levels derived from non-parametric bootstrap that runs 5000 Monte Carlo simulations of a naive random walk model over each forecast horizon from $\mathrm{k}=1$ to 10 . Joint is a $\chi^{2}$ test of joint coefficient significance. 
Table 17: The Evans and Lyons (2002a) Model Using RBS Disaggregated FFI Customer Data

\begin{tabular}{lrrlrr}
\multicolumn{3}{c}{ No Publication Lag } & \multicolumn{3}{c}{ With Publication Lag } \\
\multicolumn{1}{c}{ Euro } & \multicolumn{1}{c}{ Yen } & \multicolumn{2}{c}{ Euro } & \multicolumn{1}{c}{ Yen } \\
$\widehat{\beta}_{1}$ & & & & & \\
& -0.5039 & -0.8023 & $\widehat{\beta}_{1}$ & -0.5323 & 0.6003 \\
& $(0.7609)$ & $(0.7666)$ & & $(0.6343)$ & $(1.1922)$ \\
$\widehat{\beta}_{2}$ & & & & & \\
& 18.9184 & -97.6561 & $\widehat{\beta}_{2}$ & 5.3248 & 24.2875 \\
& $(79.1380)$ & $(75.9510)$ & & $(80.5618)$ & $(81.9591)$ \\
$\widehat{\beta}_{3}$ & & & & & \\
& -6.3183 & 188.4896 & $\widehat{\beta}_{3}$ & -49.5647 & 29.3428 \\
& $(63.3373)$ & $(60.7800)$ & & $(61.4913)$ & $(61.1588)$ \\
$\widehat{\beta}_{4}$ & & & & & \\
& -54.0679 & 102.6600 & $\widehat{\beta}_{4}$ & -28.3571 & 91.9986 \\
& $(40.6930)$ & $(37.8056)$ & & $(41.4562)$ & $(44.0591)$ \\
$\widehat{\beta}_{5}$ & & & & & \\
& -70.7078 & 218.9518 & $\widehat{\beta}_{5}$ & -107.8135 & -47.2633 \\
& $(119.1708)$ & $(105.1958)$ & & $(124.0523)$ & $(115.3405)$ \\
& & & & & \\
$R^{2}$ & -0.0168 & 0.0440 & $R^{2}$ & -0.0177 & 0.0008 \\
$A I C$ & -8.0522 & -7.4697 & $A I C$ & -7.5392 & -7.5392 \\
$D W$ & 2.0215 & 2.1600 & $D W$ & 2.0021 & 2.0560 \\
$J B$ & {$[0.0004]$} & {$[0.0000]$} & $J B$ & {$[0.0008]$} & {$[0.0000]$} \\
$A R(1)$ & {$[0.0000]$} & {$[0.1002]$} & $A R(1)$ & {$[0.9745]$} & {$[0.0000]$} \\
$A R C H(1)$ & {$[0.2145]$} & {$[0.6180]$} & $A R C H(1)$ & {$[0.7988]$} & {$[0.4671]$}
\end{tabular}

(continued...) 
Table 17 (continued): The Evans and Lyons (2002a) Model Using RBS Disaggregated FFI Customer Data

\begin{tabular}{lrrlrr} 
& \multicolumn{2}{c}{ No Publication Lag } & \multicolumn{3}{c}{ With Publication Lag } \\
& Sterling & Swiss franc & & Sterling & Swiss franc \\
$\widehat{\beta}_{1}$ & & & & & \\
& -0.4998 & -0.0552 & $\widehat{\beta}_{1}$ & 0.1478 & -0.2765 \\
$\widehat{\beta}_{2}$ & $(0.5123)$ & $(0.7704)$ & & $(0.3890)$ & $(0.6653)$ \\
& & & & & \\
& 191.5454 & -99.2095 & $\widehat{\beta}_{2}$ & -9.9745 & -115.7387 \\
$\widehat{\beta}_{3}$ & $(77.9776)$ & $(50.8914)$ & & $(91.1450)$ & $(55.1375)$ \\
& & & & & \\
$\widehat{\beta}_{4}$ & -125.2563 & 20.3724 & $\widehat{\beta}_{3}$ & -40.0325 & -51.5165 \\
& $(44.3892)$ & $(43.0460)$ & & $(49.7471)$ & $(42.9183)$ \\
& & & & & \\
$\widehat{\beta}_{5}$ & -93.5831 & 97.4216 & $\widehat{\beta}_{4}$ & -9.0412 & 21.8917 \\
& $(28.4791)$ & $(41.3283)$ & & $(29.9371)$ & $(43.5395)$ \\
& & & & & \\
$R^{2}$ & -107.9147 & 208.9912 & $\widehat{\beta}_{5}$ & -50.9129 & -16.4408 \\
$A I C$ & $(82.4005)$ & $(64.4209)$ & & $(92.4954)$ & $(75.8017)$ \\
$D W$ & & & & & \\
$J B$ & 0.1053 & 0.0328 & $\overline{R^{2}}$ & 0.0471 & -0.0036 \\
$A R(1)$ & -8.0522 & -7.3921 & AIC & -7.9957 & -7.3526 \\
$A R C H(1)$ & 2.0397 & 2.1198 & DW & 1.9434 & 2.0128 \\
& {$[0.0000]$} & {$[0.0000]$} & JB & {$[0.0000]$} & {$[0.0000]$} \\
& {$[0.6029]$} & {$[0.2309]$} & Breusch & {$[0.6185]$} & {$[0.8795]$} \\
& {$[0.4799]$} & {$[0.9564]$} & Arch $(1)$ & {$[0.4751]$} & {$[0.9974]$}
\end{tabular}

Notes: The regression equation without publication lags is:

$$
\Delta s_{t}=\beta_{1} \Delta\left(i_{t}-i_{t}^{*}\right)+\beta_{2} X_{t}^{C}+\beta_{3} X_{t}^{R}+\beta_{4} X_{t}^{L}+\beta_{5} X_{t}^{O}+\eta_{t}
$$

and with publication lags:

$$
\Delta s_{t}=\beta_{1} \Delta\left(i_{t-1}-i_{t-1}^{*}\right)+\beta_{2} X_{t-1}^{C}+\beta_{3} X_{t-1}^{R}+\beta_{4} X_{t-1}^{L}+\beta_{5} X_{t-1}^{O}+\eta_{t},
$$

where $\Delta s_{t}$ denotes the one-day exchange rate return, $\Delta\left(i_{t}-i_{t}^{*}\right)$ the one-day change in the one-month interest differential between the domestic and US economies and $X_{t}^{I}$ denotes customer order flow transacted with RBS as measured by the FFI for the four groups, $I=C$ for corporate customers, $I=R$ for real money managers, $I=L$ for leveraged money managers, and $I=O$ for other customers. Circumflexes denote estimates of the corresponding coefficient. Estimates of $\beta_{2}, \beta_{3}, \beta_{4}$ and $\beta_{5}$ and 
their associated heteroskedastic-robust standard errors, are multiplied by $10,000 . \overline{R^{2}}$ is the degrees-of-freedom-adjusted coefficient of determination; $A I C$ is the Akaike information criterion; $D W$ is the Durbin-Watson statistic; $J B$ is the Jarque-Bera test for residual normality; $A R(1)$ is a lagrange multiplier test statistic for first-order residual serial correlation; $A R C H(1)$ is a lagrange multiplier test statistic for firstorder autoregressive conditional heteroskedasticity in the residuals. Figures in square brackets denote marginal significance levels. 
Table 18: Granger-Causality Tests Using RBS Disaggregated FFI Customer Data

\begin{tabular}{|c|c|c|}
\hline & Null Hypothesis & P-Value \\
\hline \multirow[t]{4}{*}{ Euro } & $\begin{array}{l}X_{t}^{C} \Longrightarrow \Delta S_{t} \\
\Delta S_{t} \Longrightarrow X_{t}^{C}\end{array}$ & $\begin{array}{l}0.8347 \\
0.0910\end{array}$ \\
\hline & $\begin{array}{c}X_{t}^{R} \Longrightarrow \Delta S_{t} \\
\Delta S_{t} \Longrightarrow X_{t}^{R}\end{array}$ & $\begin{array}{l}0.5001 \\
0.4770\end{array}$ \\
\hline & $\begin{array}{c}X_{t}^{L} \Longrightarrow \Delta S_{t} \\
\Delta S_{t} \Longrightarrow X_{t}^{L}\end{array}$ & $\begin{array}{l}0.0995 \\
0.5280\end{array}$ \\
\hline & $\begin{array}{l}X_{t}^{O} \Longrightarrow \Delta S_{t} \\
\Delta S_{t} \Longrightarrow X_{t}^{O}\end{array}$ & $\begin{array}{l}0.4949 \\
0.0001\end{array}$ \\
\hline Yen & $\begin{array}{c}X_{t}^{C} \Longrightarrow \Delta S_{t} \\
\Delta S_{t} \Longrightarrow X_{t}^{C}\end{array}$ & $\begin{array}{l}0.7086 \\
0.0129\end{array}$ \\
\hline & $\begin{array}{c}X_{t}^{R} \Longrightarrow \Delta S_{t} \\
\Delta S_{t} \Longrightarrow X_{t}^{R}\end{array}$ & $\begin{array}{l}0.0567 \\
0.0220\end{array}$ \\
\hline & $\begin{array}{c}X_{t}^{L} \Longrightarrow \Delta S_{t} \\
\Delta S_{t} \Longrightarrow X_{t}^{L}\end{array}$ & $\begin{array}{l}0.7300 \\
0.0000\end{array}$ \\
\hline & $\begin{array}{l}X_{t}^{O} \Longrightarrow \Delta S_{t} \\
\Delta S_{t} \Longrightarrow X_{t}^{O}\end{array}$ & $\begin{array}{l}0.6873 \\
0.4125\end{array}$ \\
\hline
\end{tabular}

(Continued...) 
Table 18 (cont.): Granger-Causality Using RBS Disaggregated FFI Customer Data

\author{
Null Hypothesis P-Value
}

\begin{tabular}{|c|c|c|}
\hline \multirow[t]{4}{*}{ Sterling } & $\begin{array}{l}X_{t}^{C} \Longrightarrow \Delta S_{t} \\
\Delta S_{t} \Longrightarrow X_{t}^{C}\end{array}$ & $\begin{array}{l}0.3062 \\
0.0003\end{array}$ \\
\hline & $\begin{array}{l}X_{t}^{R} \Longrightarrow \Delta S_{t} \\
\Delta S_{t} \Longrightarrow X_{t}^{R}\end{array}$ & $\begin{array}{l}0.4805 \\
0.0398\end{array}$ \\
\hline & $\begin{array}{l}X_{t}^{L} \Longrightarrow \Delta S_{t} \Longrightarrow X_{t}^{L} \\
\Delta S_{t} \Longrightarrow X_{t}^{L}\end{array}$ & $\begin{array}{l}0.3953 \\
0.0080\end{array}$ \\
\hline & $\begin{array}{l}X_{t}^{O} \Longrightarrow \Delta S_{t} \\
\Delta S_{t} \Longrightarrow X_{t}^{O}\end{array}$ & $\begin{array}{l}0.0010 \\
0.1108\end{array}$ \\
\hline
\end{tabular}

Swiss franc

$$
\begin{array}{ll}
X_{t}^{C} \Longrightarrow \Delta S_{t} & 0.0001 \\
\Delta S_{t} \Longrightarrow X_{t}^{C} & 0.1797 \\
X_{t}^{R} \Longrightarrow \Delta S_{t} & 0.6113 \\
\Delta S_{t} \Longrightarrow X_{t}^{R} & 0.7577 \\
& \\
X_{t}^{L} \Longrightarrow \Delta S_{t} & 0.6639 \\
\Delta S_{t} \Longrightarrow X_{t}^{L} & 0.0110 \\
& \\
X_{t}^{O} \Longrightarrow \Delta S_{t} & 0.1035 \\
\Delta S_{t} \Longrightarrow X_{t}^{O} & 0.0046
\end{array}
$$

Notes: Table reports marginal significance levels - $\mathrm{p}$-values - for a $\chi^{2}$ test of joint significance of Granger-causality over 1 to 10 lags. $\Delta S_{t}$ denotes the one day exchange rate return and $X_{t}^{I}$ denotes customer order flow transacted with RBS as measured by the FFI for the four groups, $I=C$ for corporate customers, $I=R$ for real money managers, $I=L$ for leveraged money managers, and $I=O$ for other customers. A p-value below $0.05(0.10)$ indicates a significant causal relationship at a $5 \%(10 \%)$ level. 
Table 19: Out-of-Sample, Full-Information Forecast Errors Using RBS Disaggregated FFI Customer Data

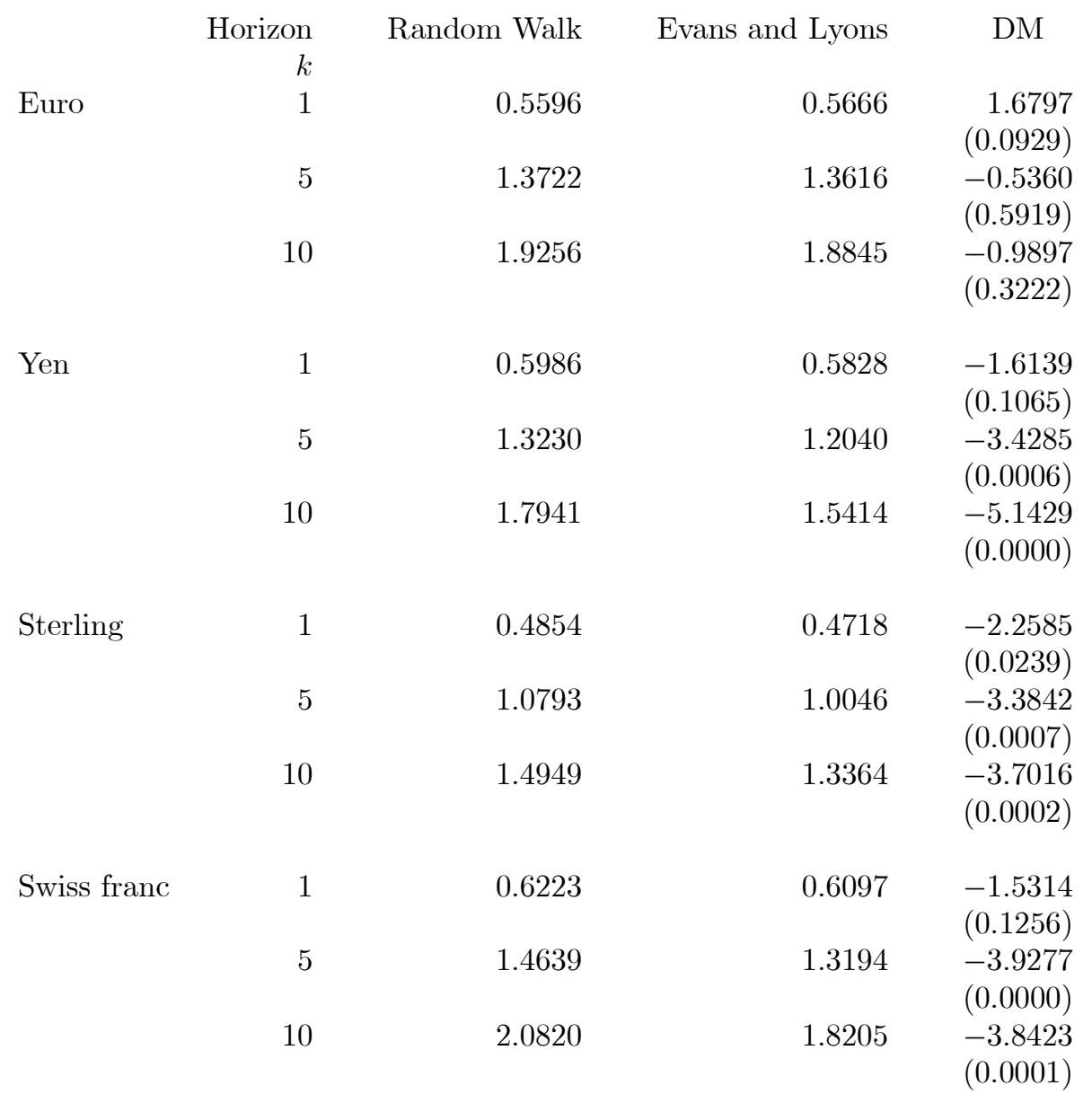

Notes: The table reports RMSFEs (multiplied by 100) for exchange rate forecasts at various horizons derived from a random walk model and the Evans and Lyons (2002a) model using disaggregated RBS customer order flow, that is:

$\widetilde{s}_{t+k}-s_{t}=\sum_{j=1}^{k} \widetilde{\Delta s_{t+j}}=\widehat{\beta}_{1} \sum_{j=1}^{k} \Delta\left(i_{t+j}-i_{t+j}^{*}\right)+\widehat{\beta}_{2} \sum_{j=1}^{k} X_{t+j}^{C}+\widehat{\beta}_{3} \sum_{j=1}^{k} X_{t+j}^{R}+\widehat{\beta}_{4} \sum_{j=1}^{k} X_{t+j}^{L}+\widehat{\beta}_{5} \sum_{j=1}^{k} X_{t+j}^{O}$

where $\widetilde{s}_{t+k}$ denotes the forecast exchange rate, $\Delta\left(i_{t}-i_{t}^{*}\right)$ the one day change in the 1-month interest differential between the domestic and US economies and $X_{t}^{I}$ denotes customer order flow transacted with RBS as measured by the FFI for the four 
groups, $I=C$ for corporate customers, $I=R$ for real money managers, $I=L$ for leveraged money managers, and $I=O$ for other customers. The estimates $\widehat{\beta}_{i}$, $i=1,2,3,4,5$ are based on data up to time $t$. We use recursive coefficient estimates starting with the initial 200 days of the sample. A negative DM test statistic indicates that Evans and Lyons forecasts are more accurate than a random walk. Figures in parentheses indicate the significance of these differences. 
Table 20: Out-of-Sample, Limited-Information Forecast Errors Using RBS Disaggregated FFI Customer Data

\begin{tabular}{|c|c|c|c|c|}
\hline & $\begin{array}{c}\text { Horizon } \\
k\end{array}$ & Random Walk & Evans and Lyons & $\mathrm{DM}$ \\
\hline \multirow[t]{3}{*}{ Euro } & 1 & 0.5596 & 0.5621 & $\begin{array}{r}0.6345 \\
(0.5257)\end{array}$ \\
\hline & 5 & 1.3722 & 1.3835 & $\begin{array}{r}0.4974 \\
(0.6188)\end{array}$ \\
\hline & 10 & 1.9256 & 1.9805 & $\begin{array}{r}1.3219 \\
(0.1861)\end{array}$ \\
\hline \multirow[t]{3}{*}{ Yen } & 1 & 0.5986 & 0.6124 & $\begin{array}{r}1.2219 \\
(0.2217)\end{array}$ \\
\hline & 5 & 1.3230 & 1.5237 & $\begin{array}{r}3.4360 \\
(0.0005)\end{array}$ \\
\hline & 10 & 1.7941 & 2.3605 & $\begin{array}{r}5.5638 \\
(0.0000)\end{array}$ \\
\hline \multirow[t]{3}{*}{ Sterling } & 1 & 0.4854 & 0.4933 & $\begin{array}{r}1.3782 \\
(0.1681)\end{array}$ \\
\hline & 5 & 1.0793 & 1.1573 & $\begin{array}{r}2.5332 \\
(0.0112)\end{array}$ \\
\hline & 10 & 1.4949 & 1.7450 & $\begin{array}{r}3.9937 \\
(0.0000)\end{array}$ \\
\hline \multirow[t]{3}{*}{ Swiss franc } & 1 & 0.6223 & 0.6101 & $\begin{array}{l}-1.5114 \\
(0.1306)\end{array}$ \\
\hline & 5 & 1.4639 & 1.5154 & $\begin{array}{r}1.1068 \\
(0.2683)\end{array}$ \\
\hline & 10 & 2.0820 & 2.2854 & $\begin{array}{r}1.7259 \\
(0.0843)\end{array}$ \\
\hline
\end{tabular}

Notes: The table reports RMSFEs (multiplied by 100) for exchange rate forecasts at various horizons derived from a random walk model and the Evans and Lyons (2002a) model using disaggregated RBS customer order flow, that is:

$$
\widetilde{s}_{t+k}-s_{t}=\sum_{j=1}^{k} \widetilde{\Delta s}_{t+j}=\widehat{\beta}_{1} k \Delta\left(i_{t}-i_{t}^{*}\right)+\widehat{\beta}_{2} k X_{t}^{C}+\widehat{\beta}_{3} k X_{t}^{R}+\widehat{\beta}_{4} k X_{t}^{L}+\widehat{\beta}_{5} k X_{t}^{O}
$$

where $\widetilde{s}_{t+k}$ denotes the forecast exchange rate, $\Delta\left(i_{t}-i_{t}^{*}\right)$ the one day change in the 1-month interest differential between the domestic and US economies and $X_{t}^{I}$ 
denotes customer order flow transacted with RBS as measured by the FFI for the four groups, $I=C$ for corporate customers, $I=R$ for real money managers, $I=L$ for leveraged money managers, and $I=O$ for other customers. The estimates $\widehat{\beta}_{i}$, $i=1,2,3,4,5$ are based on data up to time $t$. We use recursive coefficient estimates starting with the initial 200 days of the sample. A negative DM test statistic indicates that Evans and Lyons forecasts are more accurate than a random walk. Figures in parentheses indicate the significance of these differences. 
Table 21: In-Sample, Long-Horizon Forecasts Using RBS Disaggregated FFI Customer Data

\begin{tabular}{|c|c|c|c|c|c|c|c|}
\hline & $\begin{array}{c}\text { Horizon } \\
\quad k\end{array}$ & $\widehat{\beta}_{1 k}$ & $\widehat{\beta}_{2 k}$ & $\widehat{\beta}_{3 k}$ & $\widehat{\beta}_{4 k}$ & $\widehat{\beta}_{5 k}$ & Joint \\
\hline \multirow[t]{10}{*}{ Euro } & 1 & 0.1992 & 0.4694 & 0.1076 & 0.2970 & 0.2198 & 0.7960 \\
\hline & 2 & 0.3908 & 0.2158 & 0.1468 & 0.5414 & 0.3394 & 0.9056 \\
\hline & 3 & 0.4814 & 0.4360 & 0.5336 & 0.3178 & 0.4388 & 0.9638 \\
\hline & 4 & 0.4470 & 0.2946 & 0.2366 & 0.2166 & 0.1894 & 0.8245 \\
\hline & 5 & 0.3500 & 0.3204 & 0.7162 & 0.1944 & 0.1642 & 0.7597 \\
\hline & 6 & 0.4208 & 0.3678 & 0.1372 & 0.2578 & 0.3026 & 0.9257 \\
\hline & 7 & 0.2714 & 0.3852 & 0.1352 & 0.3662 & 0.3992 & 0.9909 \\
\hline & 8 & 0.2868 & 0.5020 & 0.1460 & 0.2266 & 0.1950 & 0.8874 \\
\hline & 9 & 0.1272 & 0.2328 & 0.6020 & 0.2992 & 0.1500 & 0.9108 \\
\hline & 10 & 0.0908 & 0.3088 & 0.5158 & 0.1896 & 0.0734 & 0.6741 \\
\hline \multirow[t]{10}{*}{ Yen } & 1 & 0.3172 & 0.3910 & 0.3232 & 0.0202 & 0.3480 & 0.2578 \\
\hline & 2 & 0.3186 & 0.1488 & 0.4642 & 0.2714 & 0.4540 & 0.8516 \\
\hline & 3 & 0.2856 & 0.0408 & 0.3564 & 0.2118 & 0.3002 & 0.4708 \\
\hline & 4 & 0.4338 & 0.0236 & 0.3050 & 0.3102 & 0.3110 & 0.4009 \\
\hline & 5 & 0.4464 & 0.0466 & 0.2142 & 0.2682 & 0.4766 & 0.5405 \\
\hline & 6 & 0.4558 & 0.0880 & 0.2982 & 0.3064 & 0.3270 & 0.7886 \\
\hline & 7 & 0.3914 & 0.0918 & 0.3600 & 0.3696 & 0.3170 & 0.8448 \\
\hline & 8 & 0.2774 & 0.1130 & 0.5192 & 0.2724 & 0.2934 & 0.9026 \\
\hline & 9 & 0.2998 & 0.1020 & 0.3072 & 0.4192 & 0.2154 & 0.9105 \\
\hline & 10 & 0.3094 & 0.0644 & 0.3424 & 0.4442 & 0.1046 & 0.7028 \\
\hline
\end{tabular}

(Continued...) 
Table 21 (Cont.): In-Sample, Long-Horizon Forecasts Using RBS Disaggregated FFI Customer Data

\begin{tabular}{cccccccc} 
& $\begin{array}{c}\text { Horizon } \\
k\end{array}$ & $\widehat{\beta}_{1 k}$ & $\widehat{\beta}_{2 k}$ & $\widehat{\beta}_{3 k}$ & $\widehat{\beta}_{4 k}$ & $\widehat{\beta}_{5 k}$ & Joint \\
\multirow{5}{*}{ Sterling } & & & & & & & \\
& 1 & 0.3418 & 0.4252 & 0.1850 & 0.4850 & 0.2292 & 0.8040 \\
& 2 & 0.3362 & 0.3828 & 0.3210 & 0.3080 & 0.2820 & 0.9262 \\
& 3 & 0.2610 & 0.2668 & 0.4044 & 0.4530 & 0.1340 & 0.8253 \\
& 4 & 0.2394 & 0.3846 & 0.2962 & 0.5246 & 0.0746 & 0.6701 \\
& 5 & 0.2124 & 0.5096 & 0.3282 & 0.4902 & 0.2200 & 0.9450 \\
& 6 & 0.1764 & 0.4018 & 0.1790 & 0.5822 & 0.2276 & 0.9078 \\
& 7 & 0.1972 & 0.5524 & 0.3244 & 0.2072 & 0.1886 & 0.9294 \\
& 8 & 0.1294 & 0.4080 & 0.4968 & 0.0812 & 0.1638 & 0.8148 \\
& 9 & 0.1914 & 0.4306 & 0.5736 & 0.1446 & 0.1518 & 0.9115 \\
& 10 & 0.0960 & 0.3780 & 0.5318 & 0.1126 & 0.0670 & 0.6298 \\
& & & & & & & \\
& 1 & 0.3352 & 0.0158 & 0.1258 & 0.3546 & 0.3474 & 0.2674 \\
& 2 & 0.3222 & 0.2746 & 0.3814 & 0.4200 & 0.2270 & 0.9698 \\
& 3 & 0.1978 & 0.1596 & 0.4300 & 0.4282 & 0.5764 & 0.7280 \\
4 & 0.3486 & 0.2350 & 0.4332 & 0.5384 & 0.2730 & 0.8505 \\
& 4 & 0.2638 & 0.1590 & 0.4056 & 0.2466 & 0.1978 & 0.4710 \\
& 5 & 0.2866 & 0.1222 & 0.3014 & 0.3452 & 0.1690 & 0.4498 \\
& 6 & 0.2362 & 0.2614 & 0.4920 & 0.3482 & 0.1992 & 0.6365 \\
& 7 & 0.1620 & 0.5298 & 0.4080 & 0.4102 & 0.3216 & 0.9575 \\
& 8 & 0.2254 & 0.2530 & 0.3948 & 0.5756 & 0.6350 & 0.9999 \\
9 & 0.2878 & 0.2448 & 0.3470 & 0.6600 & 0.3316 & 0.9999
\end{tabular}

Notes: The table reports marginal significance levels associated with long horizon forecasts generated from the Evans and Lyons (2002a) model using RBS FFI order flow, that is:

$$
\Delta s_{t+k}=\widehat{\beta}_{1 k} \Delta\left(i_{t}-i_{t}^{*}\right)+\widehat{\beta}_{2 k} X_{t}^{C}+\widehat{\beta}_{3 k} X_{t}^{R}+\widehat{\beta}_{4 k} X_{t}^{L}+\widehat{\beta}_{5 k} X_{t}^{O}+\varepsilon_{t+k}
$$

for $k=1,2, \ldots, 10 . \Delta s_{t+k}$ denotes the k-period exchange rate return, $\Delta\left(i_{t}-i_{t}^{*}\right)$ the one day change in the 1-month interest differential between the domestic and US economies and where $X_{t}^{I}$ denotes customer order flow transacted with RBS as measured by the FFI for the four groups, $I=C$ for corporate customers, $I=R$ for real money managers, $I=L$ for leveraged money managers, and $I=O$ for other customers. Marginal significance levels derived from non-parametric bootstrap that runs 5000 Monte Carlo simulations of a naive random walk model over each forecast horizon from $\mathrm{k}=1$ to 10 . Joint is a $\chi^{2}$ test of joint coefficient significance. 